\title{
Looking back, looking forward
}

S10 All the President's men

Professor $R$ Hermon Dowling is interviewed by Dr Ian Forgacs

S14 Penetrating insights into the ulcer story

Dr $\mathcal{F} \mathcal{F}$ Misiewicz is intervied by Professor $\mathcal{F}$ Calam

S17 Inflamed passions

Professor Fohn Lennard-Fones is interviewed by Professor T T MacDonald

S20 Being less irritable about the bowel

Dr D G Thompson is interviewed by Dr Michael Kamm

S23 Through a glass, lightly

$\operatorname{Dr} C B$ Williams is interviewed by $\operatorname{Dr} A$ I Morris

S28 Food for thought

$\operatorname{Dr} D B A$ Silk is interviewed by $\operatorname{Dr} C R$ Pennington

S32 Solid progress in a solid organ

Professor Roger Williams CBE is interviewed by Professor M $\mathcal{F} P$ Arthur

S37 From man to molecules and back again

Professor A F Markham is interviewed by Professor C $\mathcal{F}$ Hawkey

S41 'And time future contained in time past'

Sir Francis Avery fones is interviewed by Professor Michael $\mathcal{f}$ G Farthing

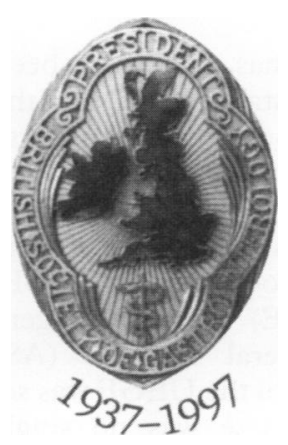




\section{All the President's men}

Professor R Hermon Dowling is interviewed by Dr Ian Forgacs

Hermon, you're
President of the
BSG and a phy-
sician. How
would rate the
health of the
BSG as it
reaches its 60 th
birthday?

RHD: In

many ways, the BSG is in excellent shape. It's a mature, thriving Society. But it is also a Society in

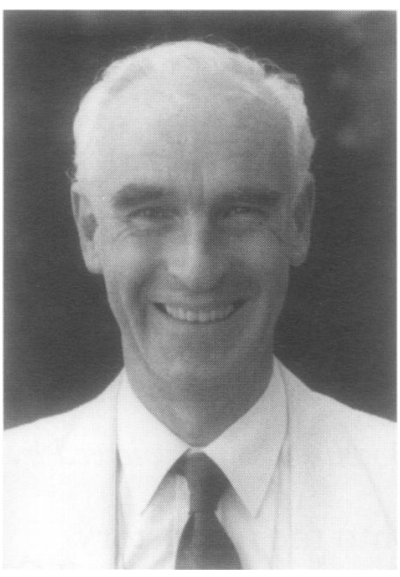
a stage of evolution. We have just voted overwhelmingly in favour of changing to one annual scientific meeting each year-in the spring. Although the Society does not want to have two meetings a year at which original work will be presented, it does want to establish some form of national meeting in the autumn. We need to consider the glue that holds the various factions within the Society together. I mean by this the surgeons, the hepatologists, the paediatricians, the basic scientists and others, and whether we need to consider some form of federal structure.

IF: Britain is hosting the United European Gastroenterology Week this October. Perhaps we could examine the BSG's international perspective a little further?

RHD: Well, the BSG is a Society of individuals, many of whom are distinguished nationally and internationally. However, we need to see Britain's contributions in the context of Europe and the rest of the world. Increasingly, we need to be competing on the international stage. Our contributions should not just be the first and the best in Britain, but hopefully the first and the best in the world.

This wider perspective has, of course, been the thrust behind the establishment of the United European Gastroenterology Federation. I needn't remind you that this is a Federation of seven existing European organisations including hepatology (EASL), pancreatology (EPC), paediatric gastroenterology (ESPGAN), endoscopy (ESGE) and GI surgery (CICD) as well as general societies (ASNEMGE and EAGE). Until the UEGF was set up just five years ago, there was no single organisation that dealt with Europe-wide aspects of our specialty as a whole. So, Britain is very proud to be hosting a major European meeting (the 6th UEGW) for the first time in 40 years. The last time Britain held an international congress of gastroenterology dealing with all aspects of our specialty was in
1956 under the presidency of the late $\mathrm{Dr}$ Tommy Hunt and Mr Hermon Taylor.

IF: How important do you think this meeting is for the future of British and European gastroenterology?

RHD: I think it is enormously important but we need to keep it in perspective because there are many other concerns for the BSG in this changing era: our relationship with Europe is just one of them. However, there has been an almost exponential growth of the UEGWs since they first began in 1992. For example, at the Paris meeting in October 1996 there were approximately 9000 participants.

IF: Do you think the BSG should should try to be the leading player in European gastroenterology? There is a feeling, I think, among some of us that much of the drive towards the development of the UEGW has been coming from mainland Europe perhaps rather than from these islands. Do you think that this is an important chance for us to establish our commitment to Europe? If you do, do you think that it's important for a country with such a scientific tradition as Britain to be leading rather than following the Europeans?

RHD: The Society is addressing this question and has set up a European Relations Group under the presidency of Professor Ian Bouchier. Britain needs to play its role but remember that the British Society of Gastroenterology is just one of 39 National Societies and Associations of Gastroenterology within $\mathrm{Eu}-$ rope. Of course, ours is one of the biggest, but we need to see this as a co-operative venture with colleagues from Germany, France, Italy, Scandinavia, and many other countries. Britain should not be trying to dominate but to lead in partnership with others.

IF: What about the BSG's role in the wider Europe. I'm thinking particularly of Central Europe?

RHD: So far, we have had links with former Eastern Bloc countries but only to a limited extent and on an ad-hoc basis. We need to learn, for example, from our Dutch colleagues. The Netherlands Society of Gastroenterology accumulated a surplus from the Holland Digestive Disease Week and rather than simply invest this in themselves, they chose to support and help young gastroenterologists from Eastern Europe. Perhaps this good Samaritan attitude should be extended and applied to Britain. This is something I would like to explore with my colleagues within the BSG, in the coming year.

IF: May we now focus on the UK just for a moment because one of the catalysts for change in the BSG has been the impact of UEGW. The 
UEGW meeting is going to replace our own national autumn scientific meeting this year. Can you tell us how you think the BSG meetings might evolve? How might we replace the autumn meeting?

RHD: I envisage that our annual scientific meeting in the spring will be a much larger meeting than at present. It is likely to involve postgraduate courses, probably lasting for just one day initially, but perhaps expanding to one and a half to two days later. The number of university venues which can accommodate our needs is diminishing - simply because of logistics and size. Therefore, in the future we may well have to turn to professional conference centres. We are moving towards a larger, more professional and more versatile meeting, but can only do so with the support and backing of the 11 existing sections within the Society, or in collaboration with a large number of other GI related disciplines. That raises the question of a federal structure. I can conceive that hepatologists, GI surgeons, paediatricians and basic scientists might join with the BSG as an umbrella organisation to set up something like a British Digestive Disease Week.

IF: You raise a number of important issues there and particularly the specialty involvement within the BSG and I want to come to that and push you a little further about that if I may. If the annual scientific meeting in the spring is going to be more along the lines of the $A G A$-style $D D W$, that does raise the issue of what should replace the autumn meeting. I think a number of gastroenterologists enjoy gathering, as the very term society implies, and are a little unsure that meeting regionally or as little groups would really replace the sense of coming together as the two BSG meetings do now. Do you see a situation where there might be just one national meeting or do you feel that the second meeting in the autumn might actually be a national meeting of some form or other?

RHD: I share your views about the importance of some form of a meeting in the autumn and I agree that this should be a national, rather than a regional, meeting. Of course, the BSG Council is there to act as a servant of the Society and the Society has already expressed its views about the need for some type of autumn meeting when the matter was discussed at the Manchester meeting in September. This whole issue is under consideration by the new Education Committee, under the chairmanship of Professor Jonathan Rhodes. He and his colleagues have made recommendations to Council about the format of the autumn meeting. They favour topic related meetings dealing, perhaps, with two or three different areas and a multi-disciplinary approach. However, we shouldn't underestimate the importance of fellowship and exchange of ideas at a national level. This will not be a meeting at which original work will be presented, but it will be an update in symposium format which is recognised for CME.

IF: So, the role of the autumn meeting is yet really to be defined and you see the spring meeting as being an enhanced academic meeting along the lines perhaps of a DDW. How can the BSG ensure the continuing support of the sub-specialist groups?

RHD: As you might imagine this is not a new topic and nor one which I'm addressing for the first time since my predecessor Paul Smith and last year's Council discussed it at length. Indeed, there has already been a meeting with leaders of various specialist organisations, to discuss this.

IF: Might I interrupt to ask if you could define the problem more precisely. I think a quite vivid example might be surgery. Aren't there a number of different groupings to which a surgical gastroenterologist might belong?

RHD: Yes, I'm pleased to focus on the example of the surgeons because it illustrates some of the difficulties in considering a federal structure. First, there is the surgical section of the BSG, but in some quarters the view has been expressed that the BSG no longer fulfils the needs of the GI surgeons: they don't get enough from our meetings. Even though approximately $20 \%$ of our members are surgeons, a much smaller percentage attends our scientific meetings. Now, in addition to the Association of Surgeons of Great Britain and Ireland, there are two new GI surgical organisations in the UK-the Association of Upper Gastrointestinal Surgeons (AUGIS) under the presidency of Professor Robin Williamson, and the Association of Coloproctology, headed by Professor Roger Grace. There is also a strong coloproctology section within the Royal Society of Medicine and there are societies concerned with surgical endoscopy and minimally invasive surgery whose membership is predominantly, but not exclusively, GI surgeons. So, to reconcile the needs and interests of these bodies is not a trivial problem. They already organise their own meetings, some of which clash with our proposed meeting in the spring. These organisations might lose status or revenue if they were to join with us in a federal structure.

IF: Do you see a potential danger there in trying to get some glue to stick these organisations together. Will they be semi-detached from the BSG? Might all the hepatologists pitch up for the day when there is a liver session at the spring BSG meeting only to disappear again at the end of their day, so they sort of drop in rather than become fully involved. How do we try to ensure that British hepatologists will still support the BSG?

RHD: First, I've got to say that British hepatology is thriving, both through the liver section of the BSG and through the British Association for the Study of the Liver (BASL). At the moment, there is a feeling in hepatological circles that the BSG is not providing liver specialists and basic scientists working on the liver with what they want. However, the shift in the timing of BASL meetings to the autumn means their membership will also have the opportunity to present original work at the BSG meeting in the spring.

The BSG needs to adapt, change and evolve. If it doesn't, there is a danger that it will fossil- 
ise. We need to talk to gastroenterology colleagues in paediatrics, basic science, liver disease and surgery, find out what they want and see if we can change our existing structure in order to satisfy their needs. If we can't, we need to consider the question of a federal structure-if that is what is wanted. But the practical politics of how representation is achieved, how autonomy is maintained and how the financial structure is organised are difficult, complex problems. I would prefer to approach this with an open mind rather than with the assumption that the BSG will be authoritarian in this respect.

IF: So you don't see a future for the BSG in the 21 st century whereby many of these other groupings have split off. Do you think that there's a common will to support the BSG?

RHD: I think there's an enormous wave of goodwill in favour of some federal structure but whether this is for the further glory of the BSG alone or whether it's a true federation of equal partners, is a matter for discussion and debate.

IF: May I move on then to discuss a possible federated structure, the larger federation within gastroenterology. As you know, the Americans have formed a federation within gastroenterology which has actually brought together some of their individual societies - including the AGA, AASLD and SSAT-one of the purposes of which is to act as a political pressure group. One wonders whether there is maybe some message here for British gastroenterologists.

RHD: I certainly see the importance of political strength and unity if we are going to influence government in terms of the practise of our specialty, funding for research and many other aspects. I would totally endorse what you say about the power of a federal structure in influencing the politicians. The setup in the United States was under the chairmanship of Don Powell, with whom I've had extensive discussions. I completely sympathise with what you say, but I believe in "government by consent" and we can only change this with the support of all the interested participants.

IF: Let's now look inwardly-a natural perspective for gastroenterologists! How important do you think the role of the BSG is in ensuring the strength of academic gastroenterology in this country? I think a number of us are concerned that although the BSG may be 60 and in robust health, perhaps academic gastroenterology has certainly had a number of minor illnesses over the past few years and can't be said, I think, to be in great shape-certainly not if you measure success by the number of MRC grants coming in. What role do you see for the BSG in promoting academic gastroenterology?

RHD: First, the BSG is developing increasing links with the British Digestive Foundation (BDF). Under its President, Professor John Lennard-Jones, the BDF is making serious efforts to raise the profile of digestive diseases, and to increase funding for clinical and basic research in gastroenterology in this country. So, the Society totally identifies with what the
$\mathrm{BDF}$ is doing and feels strongly that this should be a joint venture. However, by comparison with, for example, the British Heart Foundation, the revenue of the BDF is small. It is not in a position to endow chairs of gastroenterology nor to hand out millions of pounds a year for GI research, but I think with our links with biomedical industry and the BDF are important.

We are concerned about the amount of research funding for clinical gastroenterology. Within the BSG, the number of research fellowships supported by the MRC and the Wellcome Trust in clinical and basic gastroenterology is small. Britain's standards are high but we need to maintain them and we can only do so if there's more national funding for research.

IF: May I continue on a specifically British issue? Obviously, it's crucially important that those who purchase health care are well provided with robust information about what gastroenterologists can do and what we should be doing. The BSG has recently issued the first set of clinical guidelines. Do you think that this is an important area that the $B S G$ would wish to develop?

RHD: I think these clinical guidelines are enormously important. They were commissioned by the Clinical Services Committee which was chaired, until recently, by Professor John Bennett. He has now been succeeded by Professor Duncan Colin-Jones. In time, the guidelines will need refining and polishing. But they are very important when it comes to norms, standards and recommendations to ensure that there is a high, uniform standard of clinical practice. There is a down side, of course, and that is the prediction of health economists that doctors who follow clinical protocols will become like airline pilotsobliged to follow routines with a consequent loss of initiative. I'm not so pessimistic. I think human disease in all its variety is such that the discerning clinician can make judgementseven within the framework of evidence-based medicine, which is really what we are talking about. Of course, it will produce a more homogeneous level of practice, but at the same time a higher standard of practice and that is precisely what the guidelines are aiming for.

IF: It sounds as though the BSG is entering the new millennium in a healthy state but with a number of different challenges to meet, both internally and in the wider world, and it's a time of transition and a time of change. You're only the President for a single year. What do you think you will manage to achieve during that time and perhaps I might close by asking what you think you would like to be remembered for?

RHD: The emphasis on one year is correct. One soon realises that one serves the Society for all too brief a time. You also realise that you are working not as an individual but with a group of colleagues, very much as a team. Of course, this is a special year because of our celebratory meeting in March and because we will be hosting the European meeting in the autumn. With the help of the local organising 
committee and our professional congress organisers, I feel confident that Britain will put on a superb show, and one of which we can all feel proud. This is the first goal, but of course 1997 will set a precedent for one scientific meeting a year. The format of the new spring meeting, the concept of a federal structure and the re-organisation of a replacement meeting in the autumn are also important goals.

We have discussed the need to be rather outward looking and to consider our less well-off colleagues in eastern Europe: I would love to see some developments there. The final thing I would hope to achieve during my Presidential year is a better relationship with our colleagues in the biomedical industry. This always requires careful handling. I think we need to avoid any suggestion of a monopolistic situation or closed shop with individual companies. But we need the help of industry and they need our help. If we are going to have only one scientific meeting each year, this has implications for revenue - at a time when the Society is planning a long term lease of its premises in St Andrews Place and when it would like to collaborate more closely with the $\mathrm{BDF}$ in setting up chairs in gastroenterology. We can only do this if we have a sensible dialogue with a consortium of colleagues from the biomedical industry-not just pharmaceutical companies but also instrument manufacturers, the makers of endoscopic equipment, and publishers. On that note I might just say moving into the new millennium not only just e-mail addresses for the Society, not only CD-ROMs and video CD-ROMs, but this too in the electronic age is the way the Society has got to look for its success in the future.

IF: But I guess you wouldn't mind being remembered as the President who forged for the first time $a$ close association of a strong BSG with a flourishing UEGW. How would that epitaph suit you?

RHD: I think such an epitaph needs to be tempered with a degree of modesty and humility. I've got to repeat that our links with Europe are not my personal effort. They are the result of a team effort and such links can only be forged if there is goodwill from the majority of our members. I think there is. I also think there is a new outward-looking spirit within the Society and this was reflected in a huge mandate given to Council to organise only one scientific meeting a year, mainly, but not exclusively, so that we can contribute to the UEGWs and show our colleagues in continental Europe and the rest of the world our extraordinarily high standards. In five years time, there is no earthly reason why we should not be organising as good a meeting in Europe as the American DDW every May. That's the challenge for the future. 


\title{
Penetrating insights into the ulcer story
}

\author{
Dr J J Misiewicz is interviewed by Professor J Calam
}

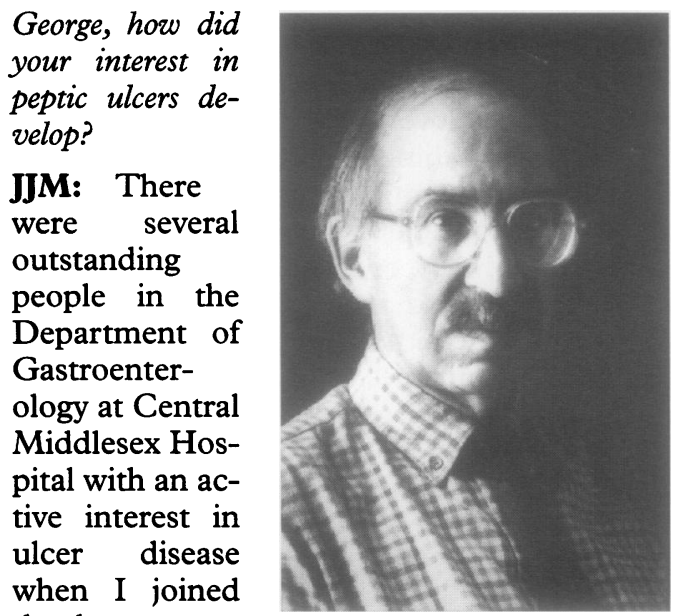

the department.

Sir Francis Avery Jones had done early pioneering work on acute GI haemorrhage. There was Dr Hugh Baron and Dr (later Professor) John Lennard-Jones with an interest in acid secretion and intragastric acidity. Dr (now Professor) Tim Northfield did an MD thesis on the diagnosis of recurrent haemorrhage. There was therefore enough going on to tempt one away from motility, which is what I was actually originally appointed to do in the then MRC Gastroenterology Unit at the Central.

Sir Francis Avery Jones was one of the first gastroscopists in this country and when I started working at Central Middlesex, we had a regular gastroscopy session long before the introduction of fibreoptic instruments; a Schindler gastroscope was used. That was another stimulus that set me thinking about ulcers. I did not really become active in ulcer research until I heard Dr Jim Black (now Sir James Black) talking about the concept of two species of receptors for histamine, the $\mathrm{H}_{1}$ and $\mathrm{H}_{2}$ receptors. I remember being very excited by the subject, and the explanation it provided why conventional antihistamine agents did not interfere with acid secretion in the augmented histamine gastric secretion test. The $\mathrm{H}_{2}$ receptor was, so to speak, ready to be discovered every time this test was done, and it was being done countless times in research and clinical laboratories at that time. No-one took the imaginative leap, until Jim Black got there, but through a different scientific route, working on animal models in vivo and in vitro. Which serves to show how fundamental and important basic research is-we neglect it at our, and our patients', peril.

I introduced myself to Jim Black after his lecture, and after that $I$ just made a nuisance of myself by writing to Smith Kline and French where he was working at the time, expressing my interest in the receptors and their antagonists, until they eventually gave in and included $\mathrm{me}$ in their plans for clinical investigation of $\mathrm{H}_{2}$ blockers. That is how I had the good fortune to be one of the first clinical investigators working with this new class of drugs, first with metiamide and later with cimetidine. This is really the point at which my practical interest in ulcer disease and acid secretion developedthe availability of these exciting new pharmacological agents.

Then I had the good luck of meeting Dr Roy Pounder (now Professor at the Royal Free Hospital), and Dr (now Sir) Godfrey MiltonThompson. Roy Pounder was a registrar in our department and was looking for a research job, but was mainly interested in immunology at that time. He was not at all interested in gastric secretion or ulcer disease. I said to him, "Roy, you can have fun and intellectual stimulation doing immunology, but we do not have an active immunology programme here. However, I do have research funds to work on acid secretion and $\mathrm{H}_{2}$ histamine receptor antagonists, which is also an intellectually attractive concept".

After much thought, Roy decided to work on $\mathrm{H}_{2}$ blockers and has since made an enormous contribution in this field. I met Godfrey Milton-Thompson at St Mark's Hospital, where we were both working in the medical IBD clinic that had been started by Avery Jones. Godfrey initiated research at the Royal Naval Hospital in Haslar (RNH Haslar), developed the clinical gastroenterology unit there and provided-at that time-wholly unique and excellent research facilities. We conducted our initial studies of 24 hour intragastric acidity down at RNH Haslar. I had worked with Godfrey using intestinal and colonic perfusion techniques measuring the effect of prostaglandins on water and electrolyte secretion at RNH Haslar previously, with Dr John Cummings and Dr Alvin Newman. Dr Richard Hunt (now Professor at McMaster University, Canada) was a prominent member of the team and he too has become a leading player in the ulcer area.

At RNH Haslar we had a very efficient research facility and excellent volunteers. We started the series of 24 hour intragastric acidity studies that defined the effect of an $\mathrm{H}_{2}$ receptor antagonist (cimetidine) on basal and postprandial intragastric acidity. The experimental model and protocol that we developed has been adopted by numerous investigators in many countries and has been extensively used for the assessment of anti-secretory drugs.

After that, the next major change in my research was the discovery of Helicobacter pylori by Marshall and Warren. I was originally amongst the disbelievers, but very soon I became convinced by the evidence. I joined the ranks of the believers and have been an ardent 
believer in the importance of helicobacter since. With Dr Hugh Baron we formed the Parkside (named after our then Health District) Helicobacter Research Group at St Mary's and Central Middlesex Hospitals-one of the few examples of effective research collaboration between two institutions. At various times, members of the group (which still continues) included Dr Robert Logan (now Nottingham University), Dr Adam Harris (Central Middlesex), Dr Marjorie Walker (St Mary's), Dr Najmar Kareem (St Mary's) and others, with papers concerning diagnosis, treatment and pathophysiological mechanisms relating to $H$ pylori.

JC: What have been the most important developments in the treatment and understanding of ulcer disease during the past 10 years?

JJM: The first development in the past 10 years, was the clinical availability of proton pump inhibitors which have so significantly improved treatment in many areas, for example, in reflux disease (GORD) and in the management of hypersecretory states. The much more fundamental and important development was the discovery of $H$ pylori by Marshall and Warren, and the avalanche of research that followed from that. Proton pump inhibitors form an important ingredient of anti- $H$ pylori triple regimens.

\section{JC: How did these discoveries emerge?}

JJM: The acid suppressing drugs, histamine $\mathrm{H}_{2}$ receptor and proton pump inhibitors, have been discovered as the result of basic pharmacological research work on animals and in vitro systems. These were developed mainly by the biomedical industry, with university-based projects as well. Helicobacter pylori emerged through painstaking bacteriological work in Perth, Western Australia, and the breakthrough was the successful culture of the organism, with careful clinical correlations to follow. Now immunology and molecular biology are providing interesting new information.

JC: Which individuals have been most catalytic in taking these ideas forward?

JJM: It is always slightly invidious to mention names, because one invariably leaves someone important out, so that I would like to be excused from listing individuals. There are numerous reviews in the literature, which will direct the reader to the key workers in this area. However, it is noteworthy that after the initial discovery in Perth, Western Australia, very substantial part of the research on $H$ pylori has been done in Europe, with important contributions from Australia and the United States.

JC: How did these discoveries influence our understanding of the molecular basis of gastrointestinal disease?

JJM: The discovery of $H$ pylori has completely changed the understanding of the pathophysiology of gastritis, ulcer disease and gastric cancer. It has radically changed and improved the treatment of duodenal and gastric ulcer disease. Gastric cancer prevention strategies can now be discussed in realistic terms. It is increasingly apparent that inflammatory mediators and toxins expressed by $H$ pylori initiate the pathological changes that follow infection with pathogenic strains of the bacterium. In other words, it is the molecular aspects of inflammation and control of acid secretion by polypeptide hormones that underlies gastritis, duodenitis and its complications, ulcer disease, MALT lymphoma or cancer.

JC: How have these developments influenced clinical practice?

JJM: These developments have influenced clinical practice in ulcer disease more than any other discovery in gastroenterology since the development of steroids and of effective acid suppressive drugs. We now have a cure for a previously incurable chronic diseases, namely gastric and duodenal ulcer. These are now known to be largely dependent on the presence of $H$ pylori in the foregut.

We now also understand the changes in gastric hyper- and hyposecretion of acid in duodenal and gastric ulcer, respectively. It is very intellectually satisfying to see how the picture is now beginning to slot into place and how all the various factors and influences are seen to interact with each other in a logical way. NonNSAID associated duodenal and gastric ulcers have been shown to be dependent on continuing chronic infection with $H$ pylori. With the development of proton pump inhibitor-based triple therapy, based on various combinations of a proton pump inhibitor with amoxycillin, or imidazole or a macrolide, there now exists a very effective cure for the infection using only one week's treatment. Eradication of the bacterium heals non-NSAID dependent ulcers, and almost completely prevents ulcer relapse. Cure of the infection also significantly decreases the incidence of re-bleeding from duodenal ulcer. This is a very major advance indeed, the full impact of which is yet to be fully appreciated. What was previously a chronic disease, subject to repeated relapses and a great deal of misery for the patient, with an appreciable incidence of life-threatening complications, is now curable. There are of course some problems, such as bacterial resistance to antibiotics, development of other symptoms (that is, GORD) after the ulcer has healed and the like. However, the gains are immeasurably greater than the losses. It is ironic that it was always taught that the stomach was sterile because of the low intragastric $\mathrm{pH}$, while all the time $H$ pylori was lurking there, below the mucus.

JC: Do you think this new information will continue to influence clinical practice in the future?

JJM: I think it will, because there are many important aspects of $H$ pylori-related research and practice that are still incomplete and are developing rapidly. Ulcers will continue to be cured, but eventually the public health issue of widespread $H$ pylori infection in countries where the incidence of gastric cancer is high will have to be faced. This will need a new capability for eradicating the organism, probably through the development of an effective 
vaccine, which might provide not only prophylaxis, but perhaps also treatment for existing infection. If a safe, effective and a reasonably cheap vaccine can be developed, it might reduce the incidence of gastric cancer globally. That this kind of large scale intervention is practicable is shown by the success of programmes involving Hepatitis $B$ vaccine, and the smallpox and poliomyelitis vaccination campaigns.

With respect to the practical issues of medical practice, I would imagine that the diagnostic techniques will develop to allow the practitioner to identify toxicogenic strains of $H$ pylori, thus facilitating a more accurate selection of patients for treatment. This, combined with carefully designed therapeutic trials incorporating prolonged periods of follow up assessment, might eventually help us to decide whether cure of $H$ pylor $i$ in functional dyspepsia is worthwhile. This has important implications in terms of resources and cost, and is a very worthwhile area for research.

JC: What role should the BSG play in ensuring the continued development of research and clinical practice in gastroenterology and hepatology?

JJM: I would have thought that fundamental research should be supported strongly. Although clinical and operational research is important, basic science is vital to the advance of gastroenterology and deserves funding.

With regard to clinical practice, perhaps the BSG should attempt to play a bigger role than so far in the education of primary health physicians. In relation to $H$ pylori, for example, one is impressed by the initiatives taken by the AGA. Their educational programmes for primary care physicians seem to be much more active than ours. This is especially important, because of the confusion that exists with regard to the choice of therapeutic regimens for the cure of $H$ pylori infection. But gastroenterology does not stop at $H$ pylori and there are many other areas in which the BSG could be active. Not only the doctors, but also the public, need to be addressed. More and more people have access to information, some good and some not so good, about their diseases, and increasingly, people get their information through the Internet. This is just one aspect which, in my view, should be developed.

Another area which the BSG could develop is the relationship with the media. I know of course that the British Digestive Foundation has been very active there in its fund-raising capacity, but perhaps a more adventurous attitude from the BSG would be welcome. High on the list of priorities could be screening programmes for colonic cancer in general, and colonoscopy service in particular. These issues concern the Department of Health, but the input of the BSG would be most valuable.

I welcome the move to a single annual meeting, an issue the Society has debated repeatedly over the years. This will allow members to attend the United European Gastroenterology Week (UEGW), which is being hosted by us this year. I am a committed European and I would hope that BSG members will support the UEGW very strongly in the future. European gastroenterology has many world leaders in its ranks. I would hope that the single annual meeting will continue to provide our customary high standard of teaching and original scientific contributions. Clinical research is having a bad time at present, partly because of serious underfunding. It is the task of our Society to try and combat the cuts and to ensure that the present emphasis on rigid certification structures, with (? over) emphasis on endoscopic procedures, will not damage the tradition of excellence in research and clinical practice for which British gastroenterology is known the world over. 


\section{Inflamed passions}

Professor John Lennard-Jones is interviewed by Professor T T MacDonald

\begin{abstract}
Thanks very much for coming along to talk about inflammatory bowel disease. The first question I would like to ask is how your interest in inflammatory

bowel disease developed, and what were the specific events or individuals which introduced you to this topic?
\end{abstract}

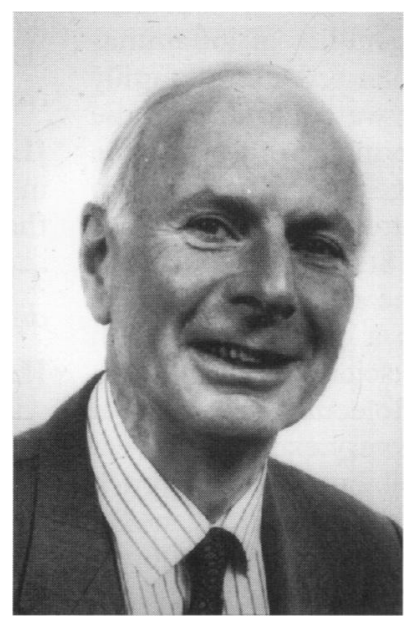

JL-J: My first memory of an interest in ulcerative colitis goes back to 1954 when I was a house physician. I can visualise the situation now. We were at the bedside on a ward round with my chief, Professor (later Lord) Rosenheim, of a patient with ulcerative colitis. He placed on the patient's bed a newly published book opened at photographs showing the striking changes in a woman after surgical treatment. The book was Ulcerative Colitis by Bryan Brooke whom I was later to know well. Another experience which influenced me, as a house physician, was a patient with Crohn's disease, a rare condition in those days. She was referred to a surgeon for resection and developed an entero-cutaneous fistula after her operation. She was a young person, probably in her thirties, and I can still visualise her in the bed. In those days we had little knowledge of electrolyte imbalance, there was no parenteral nutrition, and she died. These were two isolated events I can remember very clearly. Then I moved to Manchester where I was senior house officer to Dr Harry Howat. Again, I remember a ward round when we saw a woman with ulcerative colitis-I suddenly realised that nobody seemed to have a clear idea of her prognosis when she asked about it.

In 1957, I moved as registrar to Dr (now Sir Francis) Avery Jones and again I began to see patients with ulcerative colitis. One of my memories is of a solicitor who had an operation for toxic megacolon. As so often happened in those days, the colon perforated at operation, releasing a dreadful smell. He had a very difficult postoperative course and nearly died. It was at about that time that I began to go with Dr Avery Jones to St Mark's hospital where he held an outpatient clinic in an honorary capacity on Friday mornings. There was no day-today medical gastroenterological care in the wards at St Mark's so in my spare time I voluntarily took over the care at a junior level of inpatients at St Mark's, and continued to do so for the next seven years, during which time I was first a registrar at University College Hospital and later senior registrar at the Central Middlesex Hospital. I became conscious of the mortality after surgical treatment for colitis and wrote a paper on the topic with A B Vivian, a surgical colleague, which was published in the $B M \mathcal{A}$. We drew attention to the failure of diverting ileostomy in ulcerative colitis and the fact that deaths often occurred as a result of delay in surgery and bowel perforation. It was at this time I came under the influence of Dr (now Sir Richard) Doll who was working at the Central Middlesex Hospital conducting his classic trials on gastric ulcer. In the outpatient clinic at St Mark's, Hugh Baron, Alastair Connell, George Misiewicz, and I started to do trials on medical treatment of ulcerative colitis.

TTM: But mostly ulcerative colitis? You really didn't see much Crohn's disease?

JL-J: Yes, that is correct. At St Mark's, all surgical specimens were carefully pinned out and preserved. $\mathrm{Mr} \mathrm{H} \mathrm{E} \mathrm{(later} \mathrm{Sir} \mathrm{Hugh)}$ Lockhart-Mummery realised that some specimens were different from the classic appearance of colitis and with Basil Morson published in 1960 their classic paper on "Crohn's disease (regional enteritis) of the large intestine and its distinction from ulcerative colitis".

TTM: In the first few issues of Gut wasn't it?

JL-J: Yes, in the first volume. I remember the paper had beautiful diagrams and photographs. We began to recognise Crohn's disease in the colon and its association with anal lesions. The classification of inflammatory bowel disease became an intense interest for me and led to cluster analysis with Hywel Jones who is now working in Swansea. We worked with Dr Clive Spicer who was then director of the MRC computer unit and developed various computer models for classification of IBD. One of the facts that emerged from these analyses was that ulcerative colitis is a relatively homogeneous disease as shown by mathematical techniques. Crohn's disease, in contrast, is a very heterogeneous disease and I've always been at pains to say that the classification of ulcerative colitis and Crohn's disease is imposed by man on the clinical manifestations that we see, and we mustn't conclude that there are necessarily two separate diseases and two separate causes. I think that the current work is beginning to fulfil that thinking.

TTM: And what do you think have been the more important developments in IBD during the past 10 years?

JL-J: There has been intense immunological work, which you have been involved in. I have stood rather on the sidelines with the ever pro- 
liferating number of cytokines and inflammatory mediators. We now understand the inflammatory mechanisms much better, but, to be honest, I think the overall progress has been disappointing, because the antigen that starts the immunological process is still not known.

TTM: What about genetics?

JL-J: The first research fellow I ever had worked in 1965 on the genetics of inflammatory bowel disease. We collected a lot of family histories at that time but we couldn't take the research any further. Around 1990, it became obvious that molecular genetics was going to contribute, so we collected together all our families histories from St Mark's and took them to a geneticist. The material looked so promising that we began a collaboration with Chris Mathew and other scientists in the Division of Medical and Molecular Genetics at Guy's Hospital. We were very excited last year when we were able to collaborate with French colleagues who located a susceptibility gene for Crohn's disease on chromosome 16, though the relative risk is only 1.3. Now there are excellent results from Oxford suggesting the presence of further susceptibility genes on chromosomes 3, 7 and 12. I'm convinced that there is an environmental factor in Crohn's disease which we haven't yet identified, but I do think that this genetic work is going to answer some of our questions about the difference between ulcerative colitis and Crohn's disease. I hope that once the genes are discovered and their function is known, we may really get to the root of the pathological process. One of the most interesting papers in the past 10 years, describes a family from France in which there are seven members with Crohn's disease. The fascinating thing about that family is not only that the father and all four children have Crohn's disease, but that his wife and subsequently the wife of one of the sons developed Crohn's disease. So here we have two unrelated women developing Crohn's disease in that family, which makes one think of an infective agent.

Genetics may help identify relatives who are susceptible, however, I am not sure whether people really want to know this. If only we could find the initiating factor then if we knew who was susceptible, one might be able to separate them from this factor. I think knowledge of genetic mechanisms will lead to new treatments, as we are seeing with the antibody to TNF. We may also begin to sort out the matter of diagnosis and whether we are dealing with one disease or multiple subsets of disease, each with different susceptibilities and slightly different mechanisms.

TTM: The risk for Crohn's really goes down dramatically as you live in a contaminated environment. Could you comment on this?

JL-J: This is fascinating, because the thing that really interests me about Crohn's disease is how the incidence has increased over the past 50 odd years and this seems to have happened in all western societies. I was in South Africa about two years ago and it's interesting that in
Cape Town, Crohn's disease was previously unknown among the black population and now it's increasing. It's as if something happens to people when they adopt the western way of life. I think the gut flora must be the key to this but the organism(s) involved need not be pathogenic.

TTM: There is a classic paper from St Mark's published, I think, in 1970 by Aluwihari, who showed bacteria deep in the mucosa in Crohn's disease.

JL-J: $\mathrm{He}$ is now a very distinguished surgeon in Ceylon. That was a very important study that people seem to have forgotten about.

TTM: What do you think will be the major new discoveries in IBD during the next decade?

JL-J: That I find very difficult. I think there will be new medical treatments but I am dubious whether they are really going to be curative. I am a clinician so I look for treatments. We are bound to get new drugs as a result of the tremendous research on the inflammatory cascade. As far as surgery is concerned, I do not anticipate any enormous advance. An exception might be pouchitis. If we could understand pouchitis better, then the treatment of ulcerative colitis would be greatly improved. I see the surgical treatment of ulcerative colitis as remaining important and I think we are going to work towards an optimal level of surgical treatment. I am very impressed with the results from Copenhagen. I suspect that they manage colitis optimally because they have open access, so they can treat patients very quickly. We are going to see more evidence that better management decreases the cancer risk. They treat perhaps $35 \%$ of their extensive colitics with surgery in the first 10 years, and as a result the cancer risk is the same as in the general population. We are going to get away from the idea that surgery for ulcerative colitis is a last resort. In Crohn's disease we are awaiting the discovery of the cause. To my mind, we are going to find a cause for Crohn's disease, but I am not so sure about ulcerative colitis.

TTM: How do you think we should set research priorities in the study of IBD and ensure adequate funding?

JL-J: We must raise the public profile of IBD. The National Association for Colitis and Crohn's disease does extremely well. Patient groups are very powerful. NACC now has roughly 25000 members and is an excellent organisation. As a result, public awareness of IBD is going to increase. This may have an impact on the major funding bodies like the Wellcome Trust and the MRC. I agree that there is too little research done on IBD. Whether we should set priorities in particular areas, I am less certain. I believe that research is driven by curiosity and it is well not to direct it to much.

TTM: I have always had the feeling that perhaps IBD was a stigmatising disease.

JL-J: This is true. If you have got cancer, particularly if you are cured of cancer, you are 
very willing to go public about it. People with IBD don't usually want to go public about their illness.

TTM: Finally, what role do you think the BSG should play in ensuring the continuing development of research and clinical practice in gastroenterology and hepatology?

JL-J: In my opinion, we are falling behind in this country because we are not organising collaborative research projects. Other nations are now running ahead of us in this field.

For the genetic work, we really need a global network so that once gene loci are identified we can find the actual gene. People will have to pool their individuality so that a major study can be launched quickly and get a result.

TTM: Do you think that's really the key to $i t$-people are going to just have to say well I'm not going to be first or last author on this paper?

JL-J: When we started, clinical trials were fun because we were testing a treatment against a placebo and you got a good result with clear statistical significance in $40-60$ patients. Now investigators are looking for small differences between active treatments and you need hundreds of patients under the management of many different clinicians.

TTM: Is there anything else that you think British gastroenterology should celebrate?

JL-J: The United Kingdom should be proud of its contribution in IBD. Sidney Truelove in particular made an enormous contribution to ulcerative colitis which was not fully recognised. The early work in the 1960 s from several centres on the epidemiology and prognosis of ulcerative colitis, particularly the papers by Felicity Edwards and Sidney Truelove, were landmarks. The extraordinary reduction in the mortality of acute ulcerative colitis during my professional life has been fantastic. I think Britain has played a full part in clinical trials and development of treatments, largely helped by the National Health Service. I am afraid, and this is a political comment, that with the new organisation of the NHS, our contribution may be less. 


\title{
Being less irritable about the bowel
}

\author{
Dr D G Thompson is interviewed by Dr Michael Kamm
}

\begin{abstract}
David, how did your interest in functional bowel disorders develop? What were the specific events or individuals that introduced you to the topic?

DGT: My longstanding interest in clinical physiology starts from having done a BSc as an undergrad

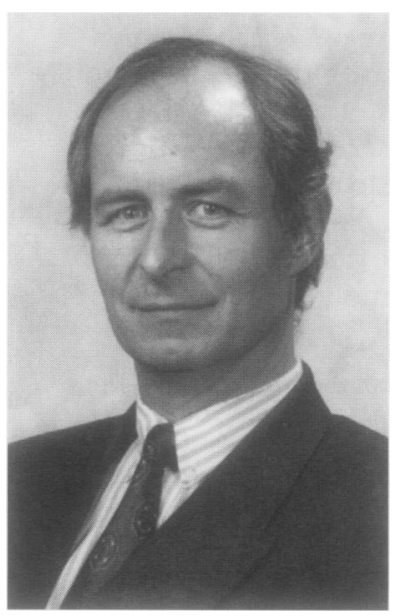
student. It was then natural for me to think of how one could apply an understanding of physiology to the symptoms suffered by patients. I have been fortunate to have had a number of quite influential mentors. In no specific order they are: John Lennard-Jones and David Wingate at The London Hospital, and Juan Malagelada and Sid Phillips at the Mayo Clinic.
\end{abstract}

MK: What have been the most significant developments in functional bowel disorders during the past 10 years?

DGT: There hasn't been a revolution in the past 10 years, more a continuous evolution and a refinement of ideas. There has been a natural assumption that motility has to be involved in functional bowel disease. However, we have realised in the past decade that we are just as likely to be dealing with a disorder of sensory information and its processing. Abnormal motility may merely be an indication that there is a disorder of neuromuscular control of the gut. We do know a lot more about clinical disorders in some areas than others and our level of knowledge decreases as we pass along the GI tract. The ease with which we understand disorders in the upper gut is probably related to the fact that the scientific basis of our understanding of the oesophagus and stomach far exceeds what we know about the lower GI tract. We have benefitted from a number of extremely good biological scientists over the past decade who have been able to demonstrate to us the fundamental aspects of the physiology of the myenteric plexus and of the extrinsic nervous system, particularly vagal control.

At a purely clinical level I think our understanding of the relation between psychological problems and symptom development is an important advance. We are now beginning to understand what motivates people to report symptoms and this understanding perhaps gets us away from a rather narrow view of functional bowel disorders as solely disorders of neurophysiology. I am reasonably confident that in many patients there will be a neurophysiological disorder to be identified but that is not what induces most people to report their symptoms to doctors.

MK: What about the work which is defining some of those pathways between the brain and the gut? Tell me about the development of detection of afferent pathways and also the work by Bueno and Taché who have looked at efferent pathways and even some of the neurotransmitters responsible for those mechanisms.

DGT: Clearly, our realisation of the major impact made by the brain-gut axis on neurological control of the gut is very important. We now know quite a lot about the gut-brain as well as the brain-gut pathways that are involved in the control of the GI tract. Taché and Bueno, along with other authors, have shown us that the higher neural centres play a fundamental role in modulation of GI function, in particular in stress. Although much of this information comes from animal models, it is clear that the information that they provide has a direct bearing on our understanding of human physiology and we'll be able to link the basic science with the clinical studies very much more in the future. A major limitation at the moment in my opinion relates to limitations in the technology available for studying in intact man what we can study with ease in animal models. Recent advances in technology have taken the science forward however. For example, a change from the use of perfused tubes for simple manometric study to more sophisticated techniques now enables us to look at gastrointestinal tone and sensory responses to distension.

Turning now from technology to therapy, it is probably true to say that although we still struggle to understand the basic pharmacology of motor and sensory function there have been a number of recent advances in therapy. We have, for example, discovered, largely by serendipity, that the antibiotic erythromycin shares a tertiary molecular structure with that of the neuropeptide motilin so that the administration of erythromycin to man mimics the action of motilin. This has now allowed us to use erythromycin and erythromycin-like molecules to stimulate gastric function, perhaps an example of how careful clinical observations, even without a clear hypothesis, allows us to make some advance.

I think it would also be wrong to ignore the advances that have been made in anorectal function. We've conveniently neglected this area for too long despite the major impact that such disorders have on morbidity. In the past 
decade in particular we began to understand the physiology of the pelvic floor in much greater detail and now can bring to bear some quite useful interventions to help patients suffering from pelvic floor dysfunction and incontinence. Perhaps the major advance has been in the power of biofeedback to alleviate symptoms. I'm not sure that anybody really would have predicted a decade ago that biofeedback would be doing so much to help these disorders, particularly in incontinence.

I think the fundamental problem that remains for clinical science, is for us to be able to make a precise clinical diagnosis of dysfunction in an intact patient, with sufficient precision to avoid the need for full-thickness biopsy. Unfortunately, the precise diagnosis of the myenteric plexus damage or even muscle damage for most of the GI tract remains impossible without full-thickness biopsies. We are making some progress with physiological techniques such as distension studies and long term manometric studies, but I think we are still a long way from being able to apply a diagnostic test and have much confidence in the findings.

MK: What about imaging? In what way do you think we have made advances in relation to functional disorders in being able to image the gut and in being able to image the brain, and I am not just talking now about $x$-ray but magnetic resonance imaging, PET scanning, functional imaging and ultrasound?

DGT: The newer imaging techniques enable us to shed new light on functional bowel problems and for us to tailor these investigations more precisely to the nature of the symptoms. Gamma camera studies have enabled us to measure intraluminal function in a way that was previously quite impossible. The application of newer and non-invasive techniques, many of which are still in their infancy, do offer major opportunities; for example, ultrasound, MR scanning techniques and in particular, the fast acquisition spin-echo MR scanning for motility. A new approach has been the use of new, highly sophisticated techniques which enable us to understand how signals from the gut are processed by the central nervous system. These include cortically-evoked potential studies, magneto-encephalography, PET scanning and functional MR imaging. These techniques enable us to see exactly how, and where, visceral signals are processed in the brain. Although they are yet to be applied in any major way to patients with functional bowel disorders, their application will certainly take us forward into a more fundamental understanding of the problem.

MK: Which individuals have been most important in the broad field of functional disorders in taking ideas forward?

DGT: I think that progress in functional bowel disorders has been the result of an interesting tension between the number of "schools" ranging from those with a largely neuropathological or physiological view of functional disorders to those at the other extreme who have viewed functional bowel disorders from a purely psychological or psychoanalytic perspective. In my view this tension has been very healthy in that it has produced movement of ideas. The physiological school for which I have a natural respect I think is probably best exemplified by the clinical physiologists, James Christiansen and Sid Phillips. These individuals have made great advances by careful clinical observation and by integrating the advances in biological science into practice. On the other hand, Doug Drossman, Grant Thompson and others have taken a more psychological view and made us realise that many patients with functional bowel disease have a strong psychological basis to their problems.

MK: Following on from the evolution of thinking in functional bowel disease, what changes have occurred in clinical practice over the past 10 years?

DGT: I think probably the major change that has occurred is a realisation that we have to take a rather more flexible view of the understanding of symptoms. It is no longer acceptable to attribute all the patient's functional symptoms to spasm or "irritability", even though these are somewhat convenient terms to use. We are also less likely to try and treat people with a purely pharmacological intervention and I think there is a progressive realisation that few of the drugs which we have used in the past have ever been demonstrated to be much better than placebo. We have also learnt that surgery is best avoided for these patients.

MK: What is the future in specific terms for drug therapies in functional bowel disorders?

DGT: At this point I need to speculate as we remain somewhat ignorant of the basic pharmacology, but if I were to have to invest some money in future therapy I would be tempted to invest it in drugs which modulate the function of sensory neurones. The natural targets would probably be 5-HT antagonists, although the experience with such agents so far is perhaps a little disappointing. Another target is peripherally acting opiate receptor/agonists. To date, however, the reality is that GI pain research is no further forwards than our understanding of somatic pain and we still do not know, for example, whether we should be targeting our therapy at the periphery or at the centre of the brain-gut axis.

MK: What about electrical intervention in modulating gut function?

DGT: Electrical intervention is an exciting possibility. It would be nice to be able to apply the equivalent of transcutaneous nerve stimulation (TENS) to our patients with so-called gut hypersensitivity and I do not see this as being too far-fetched an idea. There also seem to be major possibilities in modulating vagal afferent traffic. We already know that electrical stimulation of the vagus nerve in animals can either induce or suppress emesis and I am confident that within a short while we will have techniques for achieving the same effect in man. There has been an interest in "pacing" 
the gut for many years, but I suspect the improvement in therapy will not come from improving motility but from either enhancing or more likely, blocking spinal afferent and vagal afferent traffic.

MK: What future does surgery have in the treatment of functional disorders?

DGT: Surgery is unlikely to play a major role in the treatment of functional disorders. One could argue that in extremis in a patient with complete intestinal failure surgery can be life saving and I would agree that under these circumstances it is necessary. I would also agree that in certain specified circumstances, colectomy for colonic stasis may be the treatment of choice. In general, however, for patients in whom symptoms outweigh dysfunction, an approach through the psyche rather than from the scalpel is more likely to be of benefit.

MK: What is likely to be the role of psychological and behavioural therapies?

DGT: One of the interesting and perhaps not unexpected advances that we have made in the past decade is through psychological approaches. Their use could be regarded as somewhat empiric in many circumstances, but it seems clear to me that they do work, particularly in the severely disabled patient. Hypnotherapy shows benefit, we have seen modified psychotherapeutic techniques being of benefit, and we have seen reports that antidepressant medication is of benefit, the latter being of particular use in patients who have overt depression. Which of these is going to be the approach of choice in the future I think remains for clinical trials to elucidate.

MK: Do the traditional drugs that influence motility have a future role?

DGT: Some people would say that there has not been a single drug therapy used in the past 20 or 30 years that has been better than placebo, but I am not sure I would be quite that critical. Patients with functional diarrhoea for example are undoubtedly helped by the judicious use of opiate-like drugs, in particular loperimide or codeine, and the so-called prokinetic agents have a role in some patients. In patients with delayed gastric emptying in whom gastric emptying can be shown to be the cause of the symptoms, drugs which accelerate gastric emptying are likely to alleviate symptoms. Cisapride has been demonstrated to show benefit. Erythromycin has some promise but it remains to be seen whether it is effective long term as an oral preparation.

MK: What do you think will be the major new discoveries over the next decade?

DGT: I think the areas that I see that will take us forward will be the following: first, the discovery of afferent neural physiology and the role of afferent nerve dysfunction in so-called hypersensitivity, if you like visceral allodynia; and second, a greater understanding of the central neural processing of afferent signals. If we knew more about either of these areas we would be able to understand whether an individual who suffers pain has a problem with their gut or a problem with their brain. At present there remains considerable doubt as to where the problem actually lies.

MK: Which disciplines outside clinical gastroenterology will influence the investigation of functional disorders the most?

DGT: One of the great attractions to me of studying and managing patients with functional disorders is that successful management of patients requires a multi-disciplinary approach.

MK: How should we set research priorities in the study of functional bowel disorders and ensure adequate funding for research?

DGT: In the same way that we set research priorities elsewhere in science. That is to say, find good and interested researchers and give them the money to follow their own ideas.

MK: What part should the BSG play in ensuring continued development of research and clinical practice in gastroenterology and hepatology?

DGT: I see the BSG playing an extremely important part in the future of gastroenterology in this country. The major role that it must play is to promote an evaluative ethos among all gastroenterologists in the country. There has been a strong tradition in the UK for the consultant gastroenterologist to be as much a clinician/scientist as a technologist and one of my worries is that this important balance will be lost in the future as funding gets more difficult and the pressures to perform to targets become greater. I think the role of the BSG has to be to encourage individuals to maintain an active interest in evaluating what they do and remaining critical of what they do. Our other vital need in British gastroenterology is to identify bright people at an early phase and channel them into a career in gastroenterology. It is going to be their energy and skills that will help us to understand functional bowel disease more fully in the future.

MK: What impact do you think the explosion in molecular understanding of the basis of medicine will have on investigating and treating functional disorders?

DGT: At the moment we are still a way off applying molecular techniques to functional bowel disease. We are beginning to understand how the transduction of signals between intraluminal contents and perception occurs at a molecular level. For example, we know that food recognition involves mucosal neuropeptide release and luminal distension is equally related to 5-HT release from mucosal endocrine cells. I do not think it is too speculative to envisage a time when we are able to evaluate the function of mucosal transduction systems or even the integrity of neural innervation by biopsy. We know for example that CGRP is critically dependent, the CGRP levels in the mucosa are critically dependent on spinal afferent neural activity. We ought to be able to use such techniques to tell us whether or not such neurones are working adequately. 


\title{
Through a glass, lightly
}

\author{
Dr C B Williams is interviewed by Dr A I Morris
}

\begin{abstract}
When did you first get interested in endoscopy?

CBW: I

started working with Professor, then Dr, John Lennard-Jones at University College Hospital in 1969 at a time when endoscopy was in

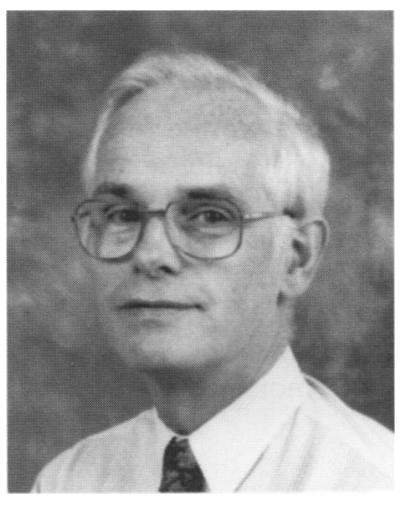
its infancy and colonoscopy did not exist. John L-J, as a great academic, was also having to develop his endoscopic skills, so we both had things to learn. I then joined L-J's team at St Mark's, and so was 'in the right place at the right time' when Sir Alan Parks returned from Japan in 1970 with the third flexible colonoscope to arrive in the UK.
\end{abstract}

AIM: Where were the other two 'scopes?

CBW: The first person in the UK to use a conventional colonoscope was Alan Dean in Edinburgh, but foremost was Paul Salmon, working for Professor Alan Read in Bristol. Paul made his career in gastroenterology and endoscopy, as you know, whereas Mr Dean changed to vascular surgery. The real British pioneer in the colon, though, was Mr Adrian Fox of Edgware General Hospital, also a vascular surgeon. He used a passive fibreoptic tube which had to be pulled up per anum by a previously swallowed string; not a technique that caught on!

AIM: You have given us the background to your involvement in endoscopy, who else stimulated your interest to develop this subject that is so close to your heart, and other peoples bottoms?

CBW: While I was working for L-J at UCH one of the problems that we had was in managing to achieve retroflexion in the stomach with the early gastroscopes. They were side-viewing and not nearly as easy to angulate as the endoscope of today. I had an opportunity to visit Professor Konrad Heinkel in Stuttgart, an enthusiastic teacher, and I learnt from him in a few seconds how to retroflex the instrument in a plastic stomach model-simply by partially angling the tip and then pushing inwards. This manoeuvre was blind and rather counterintuitive, especially with a clumsy side-viewing 'scope, and I doubt whether it would have occurred to L-J or myself for a long time without first seeing the principle in the model, and then being able be able to practise it a few times. That showed me for the first time that model teaching had something to offer and inspired me to try to do the same thing for colonoscopy at St Mark's.

AIM: How did your training interest develop from there?

CBW: Colonoscopy teaching developed a bit haphazardly. Very early on I aggravated my wife by stealing her hair-dryer tubing to make a colon teaching model. For a while it was commercialised and sold world-wide by KeyMed, but it had to be made challenging to be useful in teaching, which meant that it needed expert supervision and also could damage instruments-which was expensive and unacceptable. So I went out and bought a reject video-game for $£ 10$, one of the first generation which worked 'bats' and 'balls'. We put the potentiometers from the joy-stick controller into the up-down control and at the tip end of the shaft of a dummy endoscope and found that people would, for hours, play Ping-Pong or squash. In doing so they learnt something about dexterity, and how to coordinate left and right hands in combining angling with twist of the shaft. So we could both motivate people, unsupervised, and show them handskills in a way that they found enjoyable and productive. It didn't cost much and it didn't involve patients. That was the start of trying to develop simulator teaching, which we have since been plodding away at for a long time.

I do think that simulation is the way to go, and that fairly soon we will be able to teach endoscopic handskills without putting the patient at risk or to discomfort. Paradoxically, because of our problems in providing endoscopy, the UK has the same kind of need for teaching as underdeveloped countries, which increases my motivation to succeed, and to get the technology 'out and about'. It's also the basis of what we try to do at St Mark's'spreading the Gospel'!

AIM: I suppose another very important innovation in the past 10 years, has been the development of the video chip replacing fibreoptic endoscopes. Can you tell me how that impacted on you, on the patients and on the practise of endoscopy?

CBW: From early in my career I have routinely worked 'off screen'. Working in teaching hospitals like UCH, Bart's and St Mark's, the number of postgraduate visitors and trainees meant that over 20 years ago we attached a domestic video camera to the eyepiece of fibreoptic endoscopes so that everyone could watch the screen, rather than bicker over the side-arm teaching attachment. So, when the first videoendoscopes appeared and I was asked my opinion of them, I didn't 
(unlike some others) think that they were a gimmick and I was enthusiastic that they should be taken on. I also realised that the videoendoscope would take the endoscopist's face away from noxious fluids and would help people stand comfortably as well as letting everyone else see what was going on. I've always liked involving patients in what's going on in the procedure. The videoendoscope has turned endoscopy from a private matter for the endoscopist to being something quite enjoyable and instructive for other people, including patients and relatives-children particularly. The 'chip' endoscope has been a wonderfully liberating influence on endoscopy, quite apart from the videoprints and other bonuses that have come out of it such as remarkable resolution and high quality images. Surprisingly, even with these stupendous views, it still remains difficult to know which of the tiniest polyps is going to be neoplastic or non-neoplastic without histology.

AIM: I would agree that the videoendoscopy is much better for the whole unit, allowing the nursing staff to see what is going on and audit what the doctors are doing. They can now give you a much better idea of who is a good endoscopist as they actually see what goes on. What about getting around the colon? You've been interested in the quality of colonoscopy for some time. Can you tell us a little bit more about how you see things going as far as the quality of colonoscopy?

CBW: The challenge and the fascination, or the horror, of colonoscopy-depending on which viewpoint you take - is the problem of the handskills needed to get through this amazingly unpredictable organ. It's terribly frustrating that, even after experience of doing over 30000 colonoscopies and an interest in the skills, it's still difficult to get to the caecum in some patients, but that's also been the stimulus to think and write, and to develop new techniques to help doing or teaching it. When I started colonoscopy at St Mark's it was with a Japanese postgraduate, Tetsuichiro Muto (who is now Professor of Surgery at the University of Tokyo) and we were determined to try always to get to the caecum. Even in 1971 we were doing total colonoscopy in $98 \%$ of cases, but it sometimes took an hour or two and a lot of sedation. Even now, with a total colonoscopy rate over $99 \%$, in about one case in 50 it can take an hour or so, and a terrible struggle, to get there. Luckily in those kind of cases it's usually the endoscopist who suffers most, not the patient. I try not to be unreasonable, but most of my patients are in the cancer age group, so there's good reason to try pretty hard to see the whole colon.

With the magnetic imaging system developed with our associates at Imperial College, and also by Duncan Bell at Ipswich and his co-worker in Sheffield, we think we may have a useful answer to the tough cases. The first results were written-up for us by Brian Saunders in Gut last year. It basically works by having position-sensing coils inside the 'scope producing a running 'helicopter-view' on the computer screen of exactly what the colonoscope shaft is doing, and where the tip has got to. In some difficult cases, it's magically helpful in showing what to do to straighten things out. In others, it simply shows the extraordinary way the endoscopist modifies and straightens out the anatomy, and the awful loops which can form. At least the manoeuvring is a bit more logical when you can see what is happening on-screen, and not have to do it all by feel and guess-work.

I don't think colonoscopy will ever be made easy in all patients, but at least we now have a way to understand and teach it logically, and in many cases to make it easier to perform. Using the imager, simulator-teaching and some hands-on experience, we think it should soon be possible to teach people most of the 'tricks of the trade' of colonoscopy in only a week or two. That's what we're working towards in the Wolfson Unit at the new St Mark's.

AIM: What about remote devices of the sort that can be inserted into the rectum and guided around externally? Any ideas as to how these are developing and whether they are going to replace the colonoscope?

CBW: At the moment most of the ideas for automating colonoscopy are speculative, and those that have been tried have not proved successful. It's easy to send a robot around a rigid tube, but the trouble with the intestine is that it's so mobile and contractile, and sometimes viciously angulated. We worked in London some years ago with physicist colleagues on so-called 'intelligent', lumen-seeking endoscopes, which were computer-controlled and had servo-driven angulation controls to make the 'scope potentially self-steering. This kind of approach, perhaps with thumb joy-stick control, would at least make steering much easier than it is at present. Various robot systems have been tried and failed, but others are still being worked on. I don't think that any of them, or even the newer things like 'virtual colonoscopy' will wipe-out conventional colonoscopy though because, even with current instruments, most examinations are easy enough, and biopsy and therapy are so often needed.

What would be very useful would be to have some kind of device to insert beyond the reach of the endoscope when you're stuck in a difficult case. This might be on the outside of the 'scope or, more likely I should think, through-the-scope (TTS) like the 'mother \& baby 'scope' combination used for the biliary tree. It could either complete the look, or perhaps act as a guide for the rest of the 'scope to follow over. Alternatively, in difficult cases we could use thinner 'scopes, combined with more patient-friendly over-tubes when necessary to stop curling-up. All these kind of modifications will be easier to manage when the magnetic imager is available to show what is happening. It's a bit depressing for all concerned when someone who's previously been very tough to examine comes for follow up and there's nothing different to offer to make it easier. 
AIM: We've talked about video chips and future developments as far as getting around the colon is concerned. Have there been any other advances in the past 10 years that you feel have helped the endoscopist, and more particularly the patient?

CBW: I think it's mainly been a matter of many small improvements, which cumulatively have made a big difference. 'Scopes are so much more agile than they were, and there is such a huge range of ingenious accessories.

For instance, the very tough TTS balloons for dilating strictures, which often avoid surgery. Some simple ideas too; using submucosal injection is almost like having an extra hand available, whether to control or prevent bleeding, or to make sessile polyp resections easier and safer.

As a result of all this, many aspects of flexible endoscopy, both top and bottom, have become much more relaxed and fluent than they were. There's evidence of this in the reducing levels of medication used these days for safe and socially acceptable endoscopy. That makes the whole performance and the aftercare of the patient more civilised too. We're perfectly happy to have any accompanying relative in the endoscopy room to watch the procedure, because it's so rarely traumatic. It's also rarely necessary to 'flatten' the patient with heavy medication, which is a safety bonus. I do a number of colonoscopies with no sedation at all, although a small dose does seem to help most people through what is, after all, a rather unnatural act. I'm very much for individualising and against blanket rules, so I think it's a mistake to assume that it's right do even a brief exam like a gastroscopy without giving the patient the option of sedation. I had mine without, but I did gag a bit, and I've had several colonoscopies too; when the sigmoid's being stretched it feels a bit like having your balls squeezed- not something you want to go on too long!

I find positive enjoyment in performing an endoscopy well and kindly, having the right equipment and accessories for the job-easy to pass and easy to use. Thinking back to the ' 70 s when everything was stiff and awkward, it made the endoscopist stiff and awkward too, and the whole business much heavier than it has now become.

AIM: We've covered quite a range of the technology. Who else do you think has contributed most in the field of endoscopy, and particularly colonoscopy?

CBW: I can answer that unequivocally, because it was President Reagan. The publicity that he gave to this Cinderella area of endoscopy was magical. When it was announced that he had had colonoscopy, that an asymptomatic cancer had been found and that it was surgically resectable, it was marvellous publicity. The fact that he had it done largely because of his brother's cancer too was good advertisement for the idea of screening colonoscopy and genetic risk of cancer. People started to talk about colons and colonoscopy, and became aware of prevention. I think that, by being open about it all, Ronnie Reagan really opened up a previously dark area. He certainly made my life easier, not least that my children stopped being embarrassed about my career deviation, if I may call it that.

AIM: Well, that's an international prospective on how the profile of colonoscopy has been raised and certainly I have found the same. What other developments have influenced clinical practice, and in what way has the clinical practice of gastroenterology benefited from endoscopy?

CBW: I'm not sure that Britain has had the full benefit of what colonoscopy can offer, although the disappearance of the 'diagnostic laparotomy' and the very few resections of diverticular disease are an obvious bonus. Paradoxically though, we may benefit from being behind much of the rest of the developed world in endoscopy, because we have the potential to organise it in a controlled, professional way. The very fact that it has been a struggle in the past means that the UK, unlike for instance America, Germany or France, does not have cohorts of private practice endoscopists competing for trade. By and large we don't have their feelings of 'turf'; there is very little paranoia and a general wish to help each other, to share information, expertise, techniques or technologies and to cooperate to get the best out of endoscopy. Apart from anything else, if things can be coordinated logically, the 'one-stop-shopping' approach can be a great bonus for the patient, doing as much as possible on a single visit, without relentless repeat trips to outpatients in between. On the other side of the coin, I think that it's shameful that a combination of British conservatism and lack of resources mean that our patients get skewered with rigid instruments, rather than having flexible sigmoidoscopy available, which is the norm in the rest of the civilised world. Rigid rectoscopy is a noble art, but I think rigid sigmoidoscopy 'to the limit' is mediaeval, as well as inadequate.

I'd like to think that we can use the professional goodwill in the NHS to agree evidence-based investigation protocols that are logical, as well as feasible. In the colon this means not exaggerating follow up regimens, and deciding on worthwhile criteria for screening people at risk for colorectal cancer. The NHS ought to be well placed to do for endoscopy the equivalent of large-scale drug trials, to audit performance and check the results. The current ICRF/MRC flexible sigmoidoscopy trial is a shining example of what we can do. In countries where endoscopy is more established it's more difficult to get follow up compliance, or randomised studies or control groups because of the large number of other endoscopists the patient can go to.

AIM: What about the future? Where are we going to be over the next 10 or so years; what do you think is going to happen and how will if affect patient care? 
CBW: I think we need to start with some housekeeping. The UK has a backlog of what I would describe as 'boy scout' endoscopy, in inadequate facilities and by people who are self-taught (or badly taught) and delude themselves about their standards. In the spirit of co-operation and pride, I believe we need to try to make certain that everyone doing endoscopy is updated, that everyone teaching it is 'up to scratch' and their trainees are properly validated; having a log-book doesn't guarantee competence. Endoscopists should be prepared to accept some sort of running audit. Perhaps we should be prepared to be videotaped, the same as we are in banks or filling stations, and know that the tape might be randomly reviewed? Quality control applies to trainees, but to bosses too, so anyone doing endoscopy should be prepared to be overseen in some way. We should ensure that our fellow practitioners are doing endoscopy to a level that we would be happy with for ourselves. The BSG should agree performance standards for endoscopy and regular audit should become routine for every unit around the country if we are to be sure that the service that we now provide is really professional, and not amateurish as it inevitably was when we started up 25-30 years ago.

Everything that we do relating to endoscopy should be evidence-based if possible. The BSG is well placed to encourage this, with cooperative studies when necessary. We need to be very aware of high standards of practice, especially now that endoscopy is a front-line procedure. We have also to consider the customer's opinion at every stage, so that endoscopy becomes truly acceptable.

AIM: Yes, I would agree that the future is looking better for British gastroenterology with the agreement of the Colleges to fund the foint Advisory Group on training in endoscopy, which will set a standard for all endoscopists, be they physicians, surgeons, radiologists or general practitioners. What is your view on courses and training other than using models?

CBW: You've mentioned everyone except the nurses. They will continue to have a fairly dominant role in endoscopy, not only in maintaining standards but in subtler ways too. I think that skilled nurses will do some of the endoscopy, the limited exams at least, and they'll do it very well. They'll then also have a role in teaching trainee doctors the handskills involved, whether on devices such as simulators or by other means. That'll be a time-saver for the more senior doctors, and dedicated nurses will do it to a higher standard anyway.

There must be the same kind of approach for formal teaching of flexible endoscopy, just as the surgeons have done for laparoscopy with their chain of Wolfson-funded training units around the country. I see the future of endoscopy training as including concentrated hands-on courses for individuals or very small groups, perhaps two to three at a time and in designated centres, which will precede and supplement the apprenticeship approach. In the past, with a few honourable exceptions, the tendency has been to tantalise people en masse with one- or two-day show-off sessions by experts, which was motivating but not very effective in practical terms. Even a relatively experienced endoscopist might benefit from a 2-3 day 'sabbatical' of this kind, and a relative beginner might need up to 2 weeks to understand the whole range of possibilities. Training needs, in my opinion, to be taken on urgently, and very professionally. Relying on apprenticeship often means 'older generation' endoscopists passing on their own limitations to others.

AIM: And the technology in the future? Where are we going with that?

CBW: An exciting spin-off of videoendoscopy is that it opens up all the opportunities of the electronic age. This means not only quality views, image capture and storage, but the ability to apply image processing or enhancement, and even the possibility of real-time diagnosis. At present, spectrometry or spectrofluorimetry are experimental, but there is a good chance that they can be made to work, and without major or expensive modifications to endoscopes. We might, for instance, be able to be certain which areas might be dysplastic, or definitely are not, in a patient on chronic extensive colitis surveillance, or to spot small or flat adenomas which might otherwise be missed. The concept is immediate on-screen diagnosis, using the extra resolution of future endoscopes, with various methods of image analysis or manipulation, and possibly having the mucosa pretreated by some means to increase the effect. For therapy, we've been tantalisingly close to showing that photosensitising agents can enhance the effectiveness of laser destruction, so with better sensitisers and cheaper lasers that may still become an effective option. Doubtless other clever things will come too.

CBW: I would see the BSG as helping to 'get the act together', in other words to make sure that the various centres with ideas and adequate facilities should, where possible, cooperate to make sure that our studies are large enough and properly planned for statistical evaluation. Similarly, in evaluation of new technology we should apply the same kind of scientific rigour that we do to new drugs. This has been difficult in the past with small endoscopy units and shortage of staff; fortunately, the bonuses of endoscopy have been so obvious that it proved itself none the less. In the future things will be easier, particularly as there isn't much prejudice against endoscopy as a 'nonacademic' subject in the UK. Most of us, with the individual exception of myself as a full-time endoscopist, are doing a balanced GI practice and have other areas of academic interest as well, so we can see it in perspective.

Even so British endoscopy needs to come out of the woodwork, into the limelight and to be seen as something scientifically proper instead of being done, as you've said yourself, 
"between consenting adults in darkened rooms". The BSG can take a lead in encouraging high standards all round. Its past Working Party Reports on issues such as endoscopy unit design, staffing and disinfection have been very useful, but there are other areas where guidance is needed. Surveillance standards, record-keeping and creating a good atmos- phere for patients are some that concern me from my colonic viewpoint. Properly organised, and between friends, we should be able to do high quality studies and ensure top-level performance, which is exactly what I find rewarding about endoscopy.

AIM: Thank you for talking to me today. 


\section{Food for thought}

Dr D B A Silk is interviewed by Dr C R Pennington

\begin{abstract}
David, you trained at Guy's and Barts, you studied intestinal function and nutritional support, you have made a major contribution to nutritional management of gastroenterological patients and also many other types of patients, and your achievements have been recognised in a variety of ways. You were BSG Research Medallist, visiting Associate Professor in San Francisco, you gave the Arvid Retlin lecture at the meeting of the European Society of Parenteral and Enteral Nutrition in Paris, you were chairman of the Clinical Metabolism and Nutrition Support Group of the Nutrition Society and currently you are chairman of the British Association of Parenteral and Enteral Nutrition. How did your interests in nutrition develop and what were the specific events or individuals that introduced you to the topic?
\end{abstract}

DBAS: When I was a medical student at Guy's I was one of four students chosen following second $M B$ to take part in the first academic diploma in general biochemistry and during my year I was fortunate to meet with Professor Hazelwood who ran the course and I think he, above all, stimulated me to think academically as well as clinically. Professor Hazelwood, you remember, was interested in the structure of bile acids and it was an extraordinary, exciting year as he not only predicted the structure of bile acids in the coelocanth but this was the year when the first coelocanth was discovered and his hypothesis verified. Professor Hazelwood's influence should not in any way decry the influence of two others, namely Dr Michael Clark and Sir Anthony Dawson. Sir Anthony was then director of the department of gastroenterology at St Bartholomew's Hospital, where I was clinical lecturer and indeed Dr Michael Clark's first research fellow. Both interested me in working in the field of physiology of absorption of amino acids and peptides and of course it was my experience in this field that led to the development of my further clinical interests in the field of artificial nutrition support.

CRP: Clearly, your work in peptide absorption was a very important feature in the development of, and increased interest in, enteral nutrition. Until then, parenteral nutrition had been used extensively and enteral nutrition was little used by many cen- tres. What have been the most important developments in nutrition during the past 10 years in your view?

DBAS: This, as I'm sure you realise, is not such an easy question to answer, but I've listed six areas of development that I think have been important. The first relates to the awareness of disease-related malnutrition as a problem. Of course, the awareness of this pre-dated 1986. However, research is about researching and as we've moved forward into the second half of the $1990 \mathrm{~s}$, we again face that fact. as McWhirter and yourself have shown, that up to $40 \%$ of all patients admitted to hospital have some evidence of malnutrition. The second important development I think leads on from this and is concerned with the research that has been performed to characterise the deleterious effect that malnutrition has on clinical outcome.

Third, I think we have developed an increased awareness of human metabolism and nutritional requirements in disease during the past 10 years. This is an on-going and important area of future development. During the past 10 years, we have also seen the continuing development of different forms of artificial nutritional support; these include oral dietary supplements as well as enteral and parenteral nutrition, and I particularly refer to the development of new administration techniques which are now a key factor in clinical gastroenterology and, secondly, to the advances that are taking place, and have taken place, during the past decade in the formulation of enteral diets and TPN mixtures. Again, from the clinical standpoint, the past decade has undoubtedly seen the emergence of the importance of a multi-disciplinary approach to clinical nutrition and the setting-up of nutritional support teams throughout the country. We have moved on from the beginning of the decade where just over $25 \%$ of all units throughout the country had a nutritional support team, to 1996 where the latest figures indicate that nearly $40 \%$ of all units for acute hospitals are developing a multi-disciplinary and coordinated approach to all nutritional care.

Finally, and perhaps rather selfishly, I think a very important development in nutrition during the past 10 years has been the formation of a national multi-disciplinary group, The British Association of Parenteral and Enteral Nutrition. This has achieved much in its five years of existence and I have been very pleased to watch its continued development in association with the Small Bowel and Nutrition Group of the British Society of Gastroenterology, and I am in little doubt that as time moves on towards the next millennium that we shall 
see gastroenterologists playing a larger role in the field of artificial nutrition support.

CRP: Going back over the past decade, how did these developments to which you refer emerge? What were the important factors that led to these improvements and developments?

DBAS: I think it is fair to say that when we look where we were in the early 1980 s, we had, on the one hand, enthusiastic basic scientists forging ahead with their research and producing exciting findings. On the other hand, we had clinicians who were becoming interested in the clinical aspects of disease-related malnutrition. I think what has happened to benefit the whole field in the past 10 years, and that has actually led to the discoveries or major developments that I have outlined above, is the successful attempts that have been made to achieve closer collaboration between basic scientists and clinicians working in the field. This collaboration has now been cemented and credit must go to the Nutrition Society and for its forward-looking attitude, and its creation of the clinical, metabolic and nutritional support group and the integration of this group as a founder organisation of BAPEN. In my own unit, for example, I have had the opportunity of working with $\mathrm{PhD}$ biochemist, George Grimble. This has been a stimulating and fruitful collaboration and is merely an example of what has happened in many units throughout the UK where the expertise of basic scientists and clinicians have been moulded into a close collaboration and it is this that has led to so many developments in the field.

CRP: Which individuals do you think have been most catalytic in taking these ideas forward and developing them?

DBAS: I would dearly love to mention all those that I think have played important roles. Of the basic scientists, I think we must mention the contributions made by Professors Michael Rennie, Ian Macdonald, Peter Garlick and Bob Grimble, as well as those of his brother George Grimble and Dr Philip Caulder. Professor Alan Shenkin and Professor Barry Halliwell made major input in basic research into nutritional requirements and there are many clinicians who have achieved much in the field during the past decade. These include, in no particular order, Dr Simon Allison, Dr Chris Pennington, Dr Peter Milla, Sir Miles Irving, Dr Jon Shaffer, Dr Marinos Elia, Dr Jeremy PowellTuck, Professors Brian Rowlands, Gary Love, Alan Jackson, Ian Booth, Adam Fleck, and a particular mention to Professor John LennardJones for his outstanding contribution as chairman of the King's Fund centre report entitled "A positive approach to nutrition as treatment" and it was this report that proved to be the catalyst to the creation of BAPEN. Professor Ron Clark and Professor Ivan Johnson were the two earlier instigators behind the foundation of the CMNSG group of the Nutrition Society.

CRP: Clearly, the increased understanding of nutrition to which you refer has been very important in the management of patients with gastrointestinal disease and particularly those with intestinal failure. How do you think these developments and discoveries have influenced our understanding of the basis of gastrointestinal disease?

DBAS: I think there are two important aspects to this that are worthy of discussion. The first relates to the importance of gastrointestinal mucosal barrier function. Gastrointestinal physiologists have perhaps restricted themselves until recently to the study of physiology of intestinal absorption but as a consequence of basic developments in this area of physiology, the importance of gut mucosal barrier function is emerging. Those interested in this field have come to appreciate the deleterious effects of starving the gut, not only on intestinal morphology and function but also on gut permeability and the phenomenon of bacterial adherence. Concepts are emerging, for example, of the importance of feeding the gut in gastrointestinal disease in order to maintain gut barrier integrity and prevent translocation of endotoxins and bacteria. The deleterious effects that translocation of these have on the inflammatory response, cytokine production and the development of multiorgan failure in gastrointestinal disease is being readily appreciated.

The second area that I think the physiology of nutrient absorption in relation to gastrointestinal disease that has developed is the influence of gastrointestinal motility. In the past we have had a tendency to study nutrient absorption in isolation of the whole gut function and it is clear that intestinal motility has important influences on nutrient absorption in disease. Characterisation of the duodenal and ileal breaking mechanisms are two such examples of these, as is the effect of different nutrients on motility and transit in the small bowel.

CRP: How have these developments influenced clinical practice and do you think this new information will continue to influence the way we manage our patients in the future?

DBAS: The awareness of disease-related malnutrition as a problem will, I hope, continue to influence clinical practice. Continued education of medical staff will hopefully lead to the diagnosis of disease-related malnutrition in more patients at an earlier stage of their illness, and this will lead to the earlier implementation of nutritional support in more patients. Our increased knowledge of the deleterious effects that malnutrition has on clinical outcome is already leading to the earlier administration of nutritional support in more patients and hopefully will continue to do so. The developments in the field of human metabolism and nutritional requirements in disease are leading to the evolution of one of the most exciting developments of the decade, namely that of "nutritional pharmacology". The discovery that certain substrates may have beneficial effects on intestinal morphology and function, on the immune system, and on intestinal adaptation have led to the development of the concept of "novel substrates". Their inclusion in both enteral and parenteral formulas has, in turn, led to the development of the term 
"nutritional pharmacology", and a primary rather than merely supportive roles of artificial nutritional support in patient care. Examples of the novel substrates would be structured lipids, glutamine, arginine, nucleotides, short chain fatty acids, short and medium chain triglycerides. The added discovery of growth factors such as growth hormone and insulin growth factor-1, or IGF-1, alone or in combination with novel substrates is advancing the field very significantly. With regard to the developments in the different types of nutritional support, the increasing use of newly formulated oral nutritional supplements will, I think, continue to influence surgeons in their postoperative care of their patients. I have mentioned above how the development of new administration techniques of enteral nutrition will influence clinical practice. Most notably is the development of the percutaneous endoscopic gastrostomy or PEG feeding technique. New and improved basic gastric and naso-enteral feeding tubes have been developed during the past 10 years. Other techniques that continue to develop are those of methods for inserting post-pyloric feeding tubes and laparoscopic techniques for developing jejunostomy tubes.

The developments in the field of novel substrates have influenced and will continue to influence the formulation of enteral diets. We have seen already the benefits of work in the area of fibre research and the adaptation of concepts developing from this into the formulation of enteral diets. With regard to parenteral nutrition, we have seen during the past decade how the development of new techniques of peripheral vein infusion of nutrients has influenced clinical practice. The use of glyceryl trinitrate patches, and the incorporation of heparin and cortisone into the regimens is permitting longer term use and it is safer and simpler to insert peripheral lines. We have seen developments take place in the field of central vein parenteral nutrition and we will continue to see its movement out of the hospital and into the patients' homes. We have seen the development of new central feeding catheters and new techniques for diagnosing catheter-related sepsis; and the recognition and prevention of large vein thrombosis have been major advances that will continue to influence clinical practice in the future.

CRP: You have referred to a wealth of new knowledge and variety of new techniques that have been introduced during the past few years. Looking to the future, what do you anticipate will be the major new discoveries in this area during the next decade?

DBAS: In a sense I think I have already mentioned most of them. I would highlight the new discoveries that I expect to occur in the area of growth factors, of particular relevance to intestinal failure. I really do expect to see a huge movement forward in the field of nutritional pharmacology, in which I expect the results of important basic research on the novel substrates to be combined with the work on growth factors. I believe that artificial nutritional support will focus on two separate areas.
One is the routine support of the malnourished patient in whom nutritional support, as is often the case today, will be but one link in a chain of therapy. Importantly though in other groups of patients, for example, those who have undergone major trauma or those with major sepsis or liver or renal failure, or even patients undergoing transplantation, the application of the principles of nutritional pharmacology will lead to the development of artificial nutritional support as primary rather than just supportive therapy. I believe within the next five to 10 years we will develop a much greater understanding of the factors that control intestinal mucosal barrier function and $I$ hope that there will be major new discoveries during the next decade in three areas. The first is the achievement of greater understanding of the factors that control satiety in health and disease. The second is in the area of the timing of nutritional intervention; I hope that clinical research in the future will focus on this important area. Third, outside factors are forcing nutritional support to examine the important issue of cost efficiency.

CRP: With reference to the latter point, how should we set research priorities in the study of nutrition and ensure adequate funding not only for research but also for clinical practice?

DBAS: Your last point is an important one, namely how should we set priorities for clinical practice. Our chosen specialty, like all others, now has to convince purchasers and providers alike of the cost efficiency of nutritional support as treatment. It will become important, therefore, for investigators in the future to bring on board public health officers and health economists at a stage when studies are being designed. Clinicians in our field are no different from those in others. We are convinced of the need for making available financial support for the nutritional care of the patient. Purchasers and providers are not so easily convinced, and we must strive in the future to provide evidence of cost efficiency in everything that we do. With regard to the issue of how we should set research priorities for the study of nutrition and ensure adequate funding for this, there is little doubt in my mind how we should proceed. I have mentioned above how BAPEN is firmly linked to the small bowel and nutrition section of the British Society of Gastroenterology, and so far as gastrointestinal disease is concerned the two bodies must work together. We need to convince the Department of Health research committee and the NHS Central Research and Development Committee of the importance of research into the areas of disease-related malnutrition. Above all else, we must continue to promote the development of basic scientific research.

CRP: What role should the BSG play in ensuring the continued development of research and clinical practice in gastroenterology and hepatology?

DBAS: It is no secret that I and many of my colleagues are concerned about the deleterious effects that the Calman training programme 
may have on research in gastroenterology and hepatology and I include in this nutritional support. Indeed, one of the immediate topics of conversation is no longer "how can we acquire funds to do research?" but "how can we acquire research fellows to perform the research?". In my opinion, the BSG and other national organisations must act fast or an irretrievable gap in research progress may be immediately upon us. The BSG should therefore play a major role in lobbying the Royal Colleges and lobbying the Department of Health and NHS Executive. The development of gastroenterol- ogy into the vibrant speciality it is today has relied greatly on the efforts of its distinguished investigators and research teams. These must be maintained.

CRP: David, thank you very much for a very comprehensive overview of the current status of nutrition in gastroenterology. In spite of concerns to which you have just referred I think it is clear we can look with optimism to the future which promises great advances in the way we treat our patients and exciting new developments. 


\title{
Solid progress in a solid organ
}

\author{
Professor Roger Williams CBE is interviewed by Professor M J P Arthur
}

\begin{abstract}
Professor Williams, the main purpose of this interview is to explore your view of progress in liver disease over the past 10 years, and to ask you to predict developments in the next 10 years; but perhaps I could start by asking you how your interest developed?
\end{abstract}

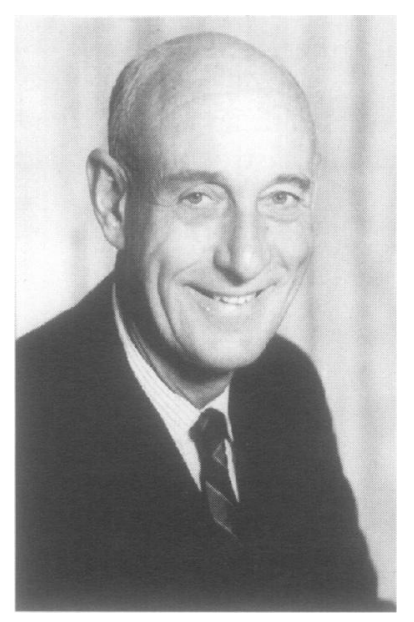

RW: My interest in liver disease dates back to when I was a national serviceman at Queen Alexandra's Hospital, Millbank. I looked after the general medical ward to which patients were admitted from all round the world with liver problems of every description.

One of the physicians to the army was Dr J G Scadding of the Postgraduate Medical School and the Hammersmith Hospital. When I had finished my National Service, I wanted to work with Sheila Sherlock but as there were no vacancies I went instead to Dr Scadding as a medical tutor with an interest in chest diseases. When Professor Sherlock left to go to the Royal Free, I was appointed as one of her first two lecturers. The other lecturer, who had just come back from the States, was Dr (now Sir) Anthony Dawson. He was rapidly promoted to a senior lecturer-I remained a lecturer, but I was then only 29 and I had jumped from SHO to senior registrar in one year so I was quite happy!

MJPA: Could you tell us a little more about your early work at the Royal Free?

RW: On starting there, Sheila told me I was to work on jaundice with Dr Barbara Billing. The first studies we did were on the effect of corticosteroids. The administration of steroids will, as you know, reduce the serum bilirubin both in acute viral hepatitis and in surgical obstructive jaundice. We did experimental studies in the rat, and a controlled clinical trial in patients which was published in the Lancet. We also produced a number of papers on the haemolytic aspects of jaundice and here I worked with Chris Pitcher, who was at the haematology department at the Royal Free.

My other main interest was in haemochromatosis. Sheila encouraged me greatly. We did liver biopsies on the apparently healthy relatives of patients with haemochromatosis and showed that the disease was likely to be a recessive one. Abnormalities in iron content were found in the heterozygotes, but not as severe as in the homozygotes, work which I did with Peter Scheuer. We then went on to study iron absorption and showed that absorption was increased in the heterozygotes. The papers attracted a lot of attention at the time. I presented the data at the Chicago Liver Meeting-my first attendance there. It brought much fire! McDonald, working in Boston at the time, had convinced America, at least, that haemochromatosis was an acquired disease related to alcoholism and that any genetic component was unimportant.

The third major area in which I worked was portal hypertension. We developed a new technique for measuring segmental blood flow in the liver. From that I went on to measurements of splenic blood flow in cirrhosis and portal hypertension using a new method for determining total spleen blood flow as well as flow per 100 grams of splenic tissue, based on the clearance of radioxenon. Further studies on blood flow in idiopathic tropical splenomegaly meant my spending three months in Kampala, Uganda, supported by the Wellcome Trust and the work on splenic blood flow, I continued at King's when I went there in August 1966.

MJPA: You are aware that the principal purpose of this series of interviews is to commemorate the British Society of Gastroenterology's Diamond fubilee year. I would like to ask you now to concentrate on the more recent period. Could you start by outlining your view of the most significant developments in hepatology over the past 10 years?

RW: It's been a good 10 years. Some developments that had started earlier have come to fruition in the clinical area, and here I am referring particularly to liver transplantation which must represent the biggest single clinical advance in the treatment of chronic liver disease in our time.

It was not until the early 1980 s with the introduction of cyclosporin that liver transplantation began to be recognised as a treatment that merited wider application. This was the conclusion of the very important NIH Development Consensus Conference that was held in 1983, and over the past 10 years there has been an enormous expansion in the number of centres and the number of transplants being carried out throughout the world. In 1996 there were some 4000 transplants carried out in the USA, and in Europe the number was over 3000 . These figures represent substantial investment in this form of treatment and patients with a whole variety of liver diseases are now being treated in this way. The results over the 10 years from 1987 to 1997 show a progressive improvement in overall survival, the one year figures are now about $90 \%$ 
for elective transplant and $70 \%$ for emergency transplants, with long term survival figures of about $75 \%$ at $5-10$ years. It is very difficult to see how you can improve on those statistics. There have been so many advances over the past 10 years with better surgical techniques, better preservation of the donor organ with UW solution so that the liver can be kept for 12 hours before being used and most recently the new immunosuppressant agent FK506. My own feeling now is that something of a plateau has been reached.

MJPA: In the early phase, when results were very variable, did you ever think that liver transplantation would become that good a treatment?

RW: That's an interesting question. In fact I have recently been writing something on the history of the Liver Unit at King's and was looking at some of the earlier records. When Professor Calne (now Sir Roy) and I started our joint programme in 1968, we were tremendously excited by what could be achieved. It was such an extraordinary leap forward and we always had some patients doing well. It must have been the third patient that we did at King's, operated on in early 1969 , who lived for four months in perfect health before developing chronic rejection. We didn't then have the right agents to control it. Then we had a woman with a massive liver cancer who did extraordinarily well for four years and four months. And we were learning so much now about liver disease in terms of reversal of disease process, the papers just flowed! Despite the many setbacks and I might say much medical opposition from those around, we never doubted that liver transplantation would be ultimately successful, though the extent to which it would be taken up might have surprised us.

MJPA: Turning away from transplantation, which other recent developments in liver disease have been really important?

RW: Clearly, this must be the discovery of hepatitis C. Worldwide, it is commoner even than hepatitis $B$, and its identification was fascinating as it involved the use of the then very new techniques of molecular biology. Even now the virus particle has not been certainly visualised. All we had initially was the serum antibody as the marker of infection. Only recently have we been able to measure viral RNA directly in blood. The extraordinary variability of the associated liver disease and its link with hepatocellular carcinoma will keep us busy for years. Indeed, it has transformed the work of hepatologists just in terms of numbers of patients. The history of the virus too is fascinating - in Europe it was spread largely during World War II as a result of blood transfusions.

As to hepatitis $\mathbf{B}$, we are beginning to see the benefits of a wider take up of universal vaccination schedules with a decrease of infection in some of the high prevalence areas of the world. In low prevalence areas such as the UK-where the vaccine has been given only to high risk groups-there has been little decrease. The argument that we should switch to universal vaccination at birth has not yet been accepted by Government; and why the manufacturers maintain such a high pricing I cannot understand.

Otherwise, in chronic liver disease, the 10 years has been marked by controlled trials of new treatments in many different clinical areas. I refer to the studies in portal hypertension of endoscopic sclerotherapy, and propanolol to lower portal pressure; to controlled trials of cyclosporin - probably superseded now by the safer ursodeoxycholic acid-in primary biliary cirrhosis, where the UK contributed the largest number of patients in the multicentre European study. Some of the benefits though are small, but at least the range of effective treatments is increasing.

MJPA: Would you like to comment on advances in the treatment of acute liver failure over this past 10 years?

RW: At the beginning of the period we were publishing controlled trials of artificial liver support based on charcoal and absorbent haemoperfusion. Sadly, they showed no statistically significant improvement in survival although with a large type II error. Subsequently, much effort went into improving the intensive care management of these patients. $\mathrm{N}$-acetylcysteine was introduced because of its beneficial effects on the microcirculation. Its use in the established phase of liver failure with grades 3-4 encephalopathy represents a significant advance with definite survival benefit shown in a controlled clinical trial and with a decreased frequency of multi-organ failure. $\mathrm{N}$-acetylcysteine improves cerebral oxygenation and with earlier control of intracranial hypertension, the frequency with which cerebral oedema develops in these patients is much less than previously. Overall survival is now around $50 \%$ of patients not fulfilling transplantation criteria. In the latter, representing $15-20 \%$ of patients overall, surprisingly good results are now obtainable. There is now too the possible use of auxiliary liver transplantation as a form of temporary liver support allowing more time for the liver to regenerate spontaneously. When that occurs the graft can be removed surgically or allowed to atrophy on withdrawal of immunosuppressive drugs.

Over the past 5 years there has been a renewed interest in liver support devices. These are mainly based on hybrid systems containing a module of cultured liver cells, derived either from pig liver or from human tumour and other cell lines. The question is always raised as to whether cells obtained in this way continue to function normally when perfused with blood/ plasma of patients with acute liver failure. The clinical trials carried out to date of the two devices that are commercially available have not shown an improved survival; but there is an enormous amount of work going on in different centres around the world in this difficult area of cell biology and bioengineering.

I should have mentioned in relation to portal hypertension the use of the TIPSS procedure 
as a new method of temporary portal decompression. I was never very enthusiastic and the tide is now turning, as it did against surgical portacaval shunts. As soon as controlled trials were undertaken, the frequency of the side effects became apparent.

MJPA: Are you totally against the TIPSS procedure, or do you think it has a place in the rescue of patients from severe variceal bleeding and perhaps in the period before liver transplantation?

RW: Its use should be restricted, I believe, to the resistant case where endoscopic treatment has not succeeded, but there are only occasional patients in that category.

MJPA: May I ask you to comment on basic scientific research in hepatology; has there been any significant progress in this area?

RW: I should have mentioned, too, other areas of more basic scientific research looking, for instance, at the development of liver fibrosis under various injurious influences. You are better able to comment on this than I am, but it does seem that there is real progress in our understanding of why and how fibrosis develops. There is now good evidence for a final common pathway in the pathogenesis of liver fibrosis, with the hepatic stellate cell (also called lipocyte, Ito or fat storing cell) playing a central role. The chances of being able to inhibit that process at some stage seem to be closer than they were 10 years ago.

MJPA: The next question is related in many ways to those that have gone before. May I ask you to name the individuals that have been most influential and catalytic in taking these ideas forward? As this is a celebration of the BSG's Diamond Fubilee please concentrate initially on UK-based individuals—you musn't be too modest!

RW: The UK contribution to hepatology over this past decade has been substantial, although its pre-eminence in Europe has been challenged by a number of centres there which you might also want to consider. Professor Sheila Sherlock's personal contribution and the work of the Royal Free Hospital has continued. My unit at King's, now in its 30th year, has, I believe, remained at the forefront of so many of the therapeutic advances. But what has happened, particularly in the latter part of this period, is the growth of a number of liver units in association with transplant units. Here I am referring to Birmingham, Edinburgh, Cambridge, Leeds, and Newcastle in alphabetical order. The research side has not extended to anywhere near the same extent although some of them have developed research facilities as well. Here, I would refer particularly to the Birmingham unit with James Neuberger and Elwyn Elias. This development has also brought more disciplines into liver work and I refer to the surgeons, immunologists, virologists, haematologists, and pathologists involved in transplantation. Notable among the liver surgeons are K-C Tan, Sir Roy Calne, Paul McMaster and among the histopathologists Bernard Portman, Roddy MacSween and Stefan Hubschner-again in alpha- betical order. Paediatric hepatology, which we haven't really touched on, has also emerged as an important clinical and academic specialty under the leadership of the late Alex Mowat.

A number of other liver centres have extended greatly over the past 10 years in terms of specific areas of liver research and here I refer to your own unit at Southampton and that of Howard Thomas at St Mary's Hospital with its major emphasis on viral hepatitis. There is also the work of Simmons in Edinburgh on hepatitis $C$.

MJPA: Would you like to expand outside the UK and identify other centres and individuals that have been particularly noteworthy?

RW: Yes, I would like to, and I am going to pick out three in Europe, however invidious this is, which have been particularly active in research. These are the Juan Rodes unit in Barcelona which includes Vincento Arroyo who has made notable advances in ascites and kidney impairment in liver disease-two areas which we have not touched on earlier. Henri Bismuth's unit in Paris where Didier Samuel works and Alfredo Alberta's group in Padua.

MJPA: May I keep you on the basic science theme and ask you to comment on the recent significant advances in our understanding of the genetic and molecular basis of liver disease?

RW: The most exciting one to me is the recent identification of the haemochromatosis gene. Ninety per cent of patients are homozygous for a change in a single amino acid in an HLA class I like gene on chromosome 6 and the lack of other mutants makes for a reasonably specific genetic test. As yet though no-one has any idea of how the abnormality influences iron absorption.

The gene for Wilson's disease has also been described, but many different mutants are found around the world-all very complicated. Again, how these influence caeruloplasmin and copper metabolism remains to be elucidated.

The work going on in relation to alcoholic liver disease in relation to a susceptibility gene is also very interesting. As you know, the chances of getting alcoholism and then alcoholic liver disease are much higher if you are identical twins born of heavy drinking parents. I heard recently in the US that they have bred a strain of rats with such a susceptibility gene.

MJPA: What are your views on the most significant molecular advances, concentrating particularly on those which may influence clinical practice?

RW: There have also been many molecular biology discoveries in relation to the expression of different genes in various processes affecting hepatocyte function and growth. For instance, different promoter genes in liver cancer. The fascinating new area of the p53 suppressor gene and its deletion allowing development of hepatocellular carcinoma with or without an underlying cirrhosis. During liver regeneration, one is able to map out in tissue the various genes that are expressed sequentially; and some of those stimulate others that are inhibitory to 
the regenerative process. Then there is your own area, with various genes being involved in the deposition and degradation of fibrous tissue and the way in which changes in liver structure develop.

Much of the extraordinary progress in our knowledge of hepatitis viruses revolves around molecular biology techniques including, as we already discussed, the identification of hepatitis $C$ virus (and also hepatitis $G$ ). It seems to me though that with the pace of technical advances and the costs involved-and this we may touch on later-only large units and organisations will be able to compete efficiently in the future. The haemochromatosis gene was identified by a commercial company with, I am told, some 300 people working on that particular project. Workers in this country at the Royal Free Hospital and at the Oxford Institute of Molecular Medicine were quite close to it, but their combined resources represented but a fraction of the commercial effort.

MJPA: What about gene therapy? Is that going to have a major impact in the treatment of liver disease?

RW: Gene therapy is very exciting in its concept. Many papers are being published on different ways of getting genes into liver cells including viral vectors but to be critical-and there have been some good reviews in Hepatology recently-there are as yet no instances where a worthwhile clinical benefit has been shown. The demonstration that hypercholesterolaemia can be corrected by introducing the appropriate gene therapy temporarily-for a month or two-was fascinating but the effect was not maintained and there are much easier ways of lowering the cholesterol level. There are, however, some potentially useful new approaches in liver tumours. If the gene for the enzyme that activates a particular cytotoxic agent can be introduced directly into the tumour cells, then not only are these destroyed but also other deposits around them through the bystander effect. The limited period of gene expression may be sufficient for a significant clinical effect.

MJPA: Presumably there are similarities to the early phase of liver transplantation? It looks almost impossible at this stage, but I am sure there will be some pioneers who will persist and make some progress.

RW: One certainly hopes so, and on the commercial side the potential profits of successful gene therapy, particularly for disease areas where there is currently no treatment, means that major investment is going to go on.

MJPA: May I ask you, now, to anticipate the future and give us your views of the most likely major discoveries in the next decade.

RW: That's always difficult. We were just touching on gene therapy, and one would be very disappointed if over that period the present early encouraging experimental studies, for instance in the Criggler-Najiar syndrome where some, but not necessarily complete, correction of deficient enzyme functions is sufficient, and in those liver tumours with clear leads to prevention as well as treatment, have not found clinical application.

What I am sure too is that we will be finding out more about individual susceptibility to liver disease. Why is it that only $15 \%$ of heavy drinkers get alcoholic liver disease-and why in so many people is the liver not affected.

In your own area of interest, I would feel fairly confident, too, that drugs will be developed that can interfere at an early stage in the cycle of events that lead to progressive fibrosis. Relatively early in the next 10 years there will also be more effective anti-viral agents to treat hepatitis $C$. The structure of the protease enzyme of NS4 region was recently identified which opens up the way to the development of protease enzyme inhibitors. Protease is the most important enzyme in hepatitis C viral replication. As with AIDS, protease inhibitors for hepatitis $\mathrm{C}$ infection are likely to be used in combination with other agents.

Will liver support devices be in routine use? I doubt it, though we are likely to see considerable progress in their development both with liver cells and with the less costly absorbent/ dialysis systems.

MJPA: Did you want to comment on the prospect of more hepatitis viruses?

RW: There is still a significant number of patients with non-A-E fulminant hepatitis so it is likely that there is another hepatitis virus to be identified. Serum samples from these patients are being intensively studied at present. There are still cases too of so-called cryptogenic cirrhosis where a virus or any other aetiological factor cannot presently be found. The latest hepatovirus - $\mathrm{G}$-was rather a disappointment. The evidence that it damages the liver is rather slight. After such an explosion of hepatitis knowledge, hepatitis research may not be as productive in the next 10 years as it has in the past. Advances in research do tend to go in phases.

MJPA: What about more advances in genetic liver disease? The most important ones have been identified, but there are a few left, for example, benign recurrent and familial cholestatic diseases. Presumably those genes might be identified in the future?

RW: I agree, the science of developmental biology is advancing so rapidly that at least some of the currently unexplained disorders of infancy and childhood affecting the liver and bile ducts will undoubtedly be sorted out.

MJPA: Would you turn now to setting out future research priorities in liver disease? How should this be tackled and how can we ensure adequate funding for liver research? Would you also comment on the role of the BSG in ensuring the continued development of research and clinical practice in liver disease?

RW: I have never been a great believer in setting priorities via a committee of experts sitting round a table. It's better to concentrate on finding the best people and giving them the facilities they require which includes laborato- 
ries and buildings in the right place and with the proper academic basis as well as clinical links to appropriate patient material.

The BSG could do much more, I would suggest, in developing both the numbers of trained research workers dedicated to liver disease and the physical structures necessary for their proper functioning. Although people come first, the right structures-and I am using structures in the wider sense, not just buildings - for them to work on are essential if the potential of modern technology is to be harnessed. If they are put in place, then I think the advances and the new knowledge would come through. We must remember also that basic and applied research is increasingly international-the almost instant methods of communication now available should mean more rapid progress as well as less duplication of effort.

Ever since I was President of the BSG I have been pushing too for the establishment of more academic chairs in gastroenterology. In recent years many more gastroenterologists have been given professorial titles, but in the majority if not all of these, the chair is a personal one and relates to an NHS funded clinical post with little new or extra time for research.

It is right for the BSG to be taking such a major role in enhancing gastroenterological research. Good clinical practice is based as we all know on research, and if scientists are brought together with clinicians, in the end the patient will be better treated. Although as I have already referred to the success of liver transplantation has forced various liver centres into being, they vary greatly in their interest or indeed facilities for research. The BSG's priorities in my view should therefore be to look at the 'structures' which underpin liver research in the UK-how many properly set up liver centres do we have; how many should there be in relation to the population distribution and the universities? How they are to be equipped? And above all how are the scientists and clinicians that are needed to lead them to be encouraged and trained?

MJPA: It is unlikely that the BSG itself would be able to afford these developments, so presumably you see its role as influencing and educating the $M R C$, the Wellcome Trust and other AMRC charities about these issues in hepatology and gastroenterology?

RW: Better collaboration between those organisations that you mention and the other charities that specifically support the liver research would clearly help. Gastroenterology in general and liver disease are not scoring as well with the MRC and with the Wellcome Trust as they did in the past. The answer of these bodies is that if the application is good enough it will get funded. But it is difficult to get a top rating application together without the back up of a unit where scientific expertise and background studies are available - another reason for the need to concentrate on 'structures'.

MJPA: Professor Williams, thank you for your time and for an interesting and enlightening interview. 


\title{
From man to molecules and back again
}

\author{
Professor A F Markham is interviewed by Professor C J Hawkey
}

\begin{abstract}
Professor
Markham, you trained as an organic chemist with an interest in nucleic acids and entered medical school at the age of 30. From this background of dual training what views have you formed of the contribution that clinical academics can make. Many would say these folk are just overpaid and under-skilled scientists.
\end{abstract}

AFM: My own opinion is that this is not the case. The great strength of clinical scientists is that they understand clinical problems and their significance. They understand how difficult the practice of medicine can be. As a nonclinical scientist I never felt I had sufficient grasp of what the real clinical problems were in the first place. If you don't know what target to point your weapons at, it really doesn't matter how powerful they are. But medicine is a unique smorgasbord in terms of the training it provides. You get to look, at a relatively superficial level, at a very wide spectrum of things. I believe that's a great strength of medical training and I would defend the clinician/scientist against all comers.

In the lab, I think the ideal mix is for our clinical research fellows to train alongside nonclinical postdoctoral fellows, because both have things to learn from one another. I so often see scientists and clinicians failing to communicate for all sorts of reasons and I think they have to be put together and encouraged to work in harmony and to understand one another. In the USA, bioscience is dominated by the $\mathrm{MD} / \mathrm{PhD}$-an animal we really don't train anything like enough of in the UK. It saddens me to see young doctors in the UK being encouraged away from research (especially fundamental research) during their medical training. By the time they wish to move into research, so many years have passed that they are coming to it a little late. I would like to see more $\mathrm{MD} / \mathrm{PhDs}$ where people take time off during their clinical training to pursue research in depth and then return to the clinic with some research skills in place. The Calman process worries me deeply in this regard.

CJH: Do you think everybody should do research, or that it can actually be rather harmful?

AFM: I don't think everybody in training should do research. Far too many clinicians who have no inclination to go into research have felt they must complete their "research year" to get a consultant position. I think that's wholly inappropriate. However, I do think that it would be tragic if clinicians were going through their training with no exposure to research philosophy. Although not every gastroenterologist should be expected to undertake periods of laboratory research, they should be networked into research so that their clinical work is incorporated into bigger epidemiological studies. Of course we will continue to have distinguished people who are doing fundamental biomedical research in gastroenterology, but I think that we lose out because not every practising gastroenterologist is linked into large clinical studies in some way. There is a major role for the BSG to make that happen by forming a better umbrella network for research in gastroenterology and hepatology in the UK.

CJH: That sounds essentially like a clinical trials/epidemiological role especially for rare conditions.

AFM: I believe that's exactly right and wholly appropriate. Think of the Cinderella disease in gastroenterology-irritable bowel syndrome. I guess in amongst that tidal wave of patients must be some who have a familial form of this condition. It is probably only by going nationwide and getting every clinician to think about his irritable bowel disease practice that those few patients will be brought to our attention and give us the material to gain some genetic insights into what is otherwise a fairly intractable problem.

CJH: Supposing you wanted to tackle precisely that question of a genetic basis for at least some forms of irritable bowel syndrome, what clinical evidence would you look for to suggest that that was the case and then what would be your approach to trying to identify the precise genetic abnormality?

AFM: Well, I guess we have a fine working model from the distinguished work of Derek Jewell and his colleagues at Oxford in inflammatory bowel disease. The first thing that points towards a genetic basis for a condition like irritable bowel syndrome would be twin studies and one would be looking to see whether there is concordance for the condition in twins, particularly monozygotes.

CJH: Presumably that would be best in identical twins reared apart if possible because of early life influences. Supposing I had done a family study and I had found a reasonably well defined clinical sub-type of irritable bowel and I had done some twin studies (and fortunately they were twins reared apart) and I had found there was a high concordance between these twins. What would you want me to do to help you study that genetically? 
AFM: Classically we must assume a condition like this is polygenic, with a number of different genetic influences and environmental factors as well. What this requires is study of affected sib pairs looking for a particular genetic marker inherited by the affected sibs more frequently than would be expected by chance. If that is the case, then that marker may be linked to the disease. If you study enough affected sib pairs and that skewed segregation is found consistently, then the implication is that the gene responsible is somewhere near that genetic marker.

CJH: So you decide what you think IBS is about functionally and then sequence genes which are near the marker and have appropriate normal function and look for mutations. We will leave aside the fact that you might have to look at neurotransmitter genes.

AFM: The advantages of a very common condition like this, if you have an effective network, is that you can collect a lot of sib pairs. A large number of patients enables you to narrow the target region even more so that your search may well be in a smaller region and therefore involve a smaller number of genes. This is then an exercise in resources. The job can be done if you can throw enough effort at it. The model will be quite clearly established over the next five years in inflammatory bowel disease and that will point towards the way the same exercise can be undertaken in irritable bowel syndrome. I would be very surprised not to see the first speculative studies starting to come though over the next couple of years.

CJH: We've started to look forward, but let's just look back a bit first of all. If you look back over the past 10 years, what are the most significant developments in molecular biology both in general and from a gastroenterology and a British perspective?

AFM: In the past 10 years there have been a number of landmark technical advances. The first one (which doesn't quite fall into the past 10 years) is the polymerase chain reaction (PCR). That first emerged in 1985, but strangely, given its preeminence in 1997 as a technique, its significance was simply not appreciated until about 1988 . It was also technically rather difficult to perform at that stage. PCR has transformed molecular biology and medicine.

A second development has been the discovery of highly polymorphic genetic markers in humans. That has transformed our whole approach to human genetics. The key discoveries were those of Alec Jeffreys in the UK in the late $1980 \mathrm{~s}$, the mini-satellites, and of John Weber from Minnesota who discovered microsatellites. These discoveries opened the way to factory scale operations aimed at identifying vast numbers of highly informative genetic markers distributed throughout the human genome. These make it easy for us to localise disease causing genes. None of the things that we now take for granted in studying the genetic basis of, for example, inflammatory bowel disease, would have been possible without this new generation of genetic markers.
The other component of molecular genetics which has been vital in driving advances has been the development of novel techniques for positional cloning. Cloning of large amounts of DNA has enabled us to make detailed physical maps of the human genome. If I were to single out one cloning technique of greatest importance, it would be yeast artificial chromosomes. These enable one to clone pieces of DNA of about a million base pairs in length which makes it easy to map accurately where the genes are on chromosomes and quickly focuses on specific genes to consider as candidates for particular diseases.

Another technique to appear in the past decade is transgenic technology. This has a major impact in all branches of biomedicine, not least in gastroenterology. There are major contributions from people like Jeffrey Gordon in the USA who described a transgenic mouse line that develops something that resembles Crohn's disease. There are a number of transgenic knockout models that develop inflammatory bowel disease. There are transgenic models of colonic cancer with mutations in the gene which causes familial polyposis coli in humans. All of these help to prove cause and effect in pathology and in the longer term, should provide us with model systems to evaluate novel therapies.

CJH: There are considerable financial incentives in this area. Do you want to say something about the role of industry in collaboration with academic units in this type of research?

AFM: It has been very interesting to watch it develop. In some ways the pharmaceutical industry majors were left at the starting gate 10 years ago in terms of their adoption of genetic approaches to the drug hunting process. A component of the problem was lack of access to patient material which has been vital in all of this genetic research into gastrointestinal disease. I think that most of the pharmaceutical companies quietly carried on in their traditional way-drug hunting with established targets. More recently, there has been a sharp swing in the opposite direction which is probably slightly over enthusiastic. Many drug companies now see "genomics" as the source of all their new therapeutic targets. I think that is overly optimistic.

CJH: Traditionally, British gastroenterology may have adopted a handmaiden role to industry as the supplier of patients for trials. Is there an analogous role that could be adopted as a supplier of patient material?

AFM: Without question. You can't do genetic studies without patient material. It is as simple as that. This is now a major growth industry in the USA. Clinicians are setting up companies in which groups of patients are screened to identify genes for important diseases. There are several such businesses in the USA already. Access to such groups of patients is of great commercial value. I think some of the ethical questions this raises are very complex and difficult. Nevertheless, there is a role for the pharmaceutical industry in some of 
the factory scale screening that goes on in genetics. Potentially, the BSG could act as the broker in that process, arranging to make material available to the pharmaceutical industry, whilst dealing with some of the ethical issues that arise.

CJH: May we talk about those molecular studies that are already influencing our understanding of the molecular basis of gastrointestinal disease. How about the work that is really starting on the human genetics of the response to Helicobacter pylori?

AFM: This will be very important work particularly in the way that the host's genetic make-up determines the capacity of $H$ pylori to induce malignancy. That's a major question to answer in terms of screening and public health. If you can identify individuals who are at high risk of developing $H$ pylori associated malignancies, you will want to keep them as $H$ pylori free as possible.

CJH: What about the strategy of looking at expression of different genes which occur within the epithelium as a consequence of $\mathrm{H}$ pylori infection? Is that likely to be a fruitful strategy?

AFM: You never know until you try. I do see that as a productive area of research. You can imagine doing some relatively simple experiments with $H$ pylori in gastric epithelial cells in culture simply to ask the question: what genes get switched off and what genes get switched on?

CJH: Going beyond $\mathrm{H}$ pylori, are there any other areas in which molecular genetics is making a big difference in gastroenterology?

AFM: Cancer is still an area in which molecular genetics has an enormous impact. The paradigm is colorectal cancer and familial polyposis coli where a rare Mendelian form of a common disease has provided enormous insights into the molecular aetiology of the common form of the condition. The British contribution was that the initial linkage to chromosome 5 was established by Bodmer and colleagues at ICRF. Cloning of the APC gene has led to a working model of what genetic changes occur during the development of colorectal malignancy. That model is unique among the malignant diseases in its level of detail and has also shaped our thinking about all other cancers, particularly other gastrointestinal cancers. Subsequently, cloning of genes responsible for hereditary non-polyposis colon cancer has had an enormous impact and raises serious questions of how we manage this problem in the community. More and more patients are coming forward with a family history of colorectal cancer, who need genetic counselling and their genes analysed for mutations. Recent advances in our understanding of pancreatic cancer are following along the pathway that colorectal cancer has mapped out for us. In the past 12 months the gene has been found for a condition called hereditary pancreatitis which is a dominant condition that predisposes to pancreatic cancer. Other tumour suppressor genes for pancreatic cancer have been cloned, and what emerges is that these genes are com- ponents of similar and related cellular pathways to those involved in colorectal cancer. They are not the same genes but their proteins interact one with the other, to disrupt epithelial junctions. A picture is starting to emerge that different gastrointestinal cancers are part and parcel of the same fundamental problem-a lack of proper interactions between gastrointestinal epithelial cells in whatever location.

The other aspect of gastrointestinal cancer molecular biology that needs to be mentioned is recognition of the role of mutations in p53. In terms of British contributions, obviously David Lane in Dundee has led the way in highlighting the importance of p53 as the most common genetic problem in human malignancies across the board.

CJH: Although people tend to think of cancer in terms of proliferation, they may be aware of $p 53$ and its involvement in apoptosis. You are hinting also at the importance of polarity in normal epithelial cells and its loss in cancer. Do you think there is a flip-side to studying cancer in understanding the importance of polarity for normal function?

AFM: I think that is absolutely true. Again, I lapse back to APC as an example. Although there was great rejoicing when APC was first cloned, 5 years on it would be fair to say that we understand very little about how this protein, whose absence leads to cancer, actually works in the normal gut epithelial cell. There is a message here about how we fund research. Research funding tends to be sucked into exciting "lets find a gene for disease X" projects and tends to be more difficult to command for the years of subsequent work that go into establishing exactly how the protein functions and what goes wrong with it. This is often more important than finding out that it exists in the first place. I believe we have an enormous amount to learn from genes that are lost in gastrointestinal cancers because, by definition, their proteins have an important role in the functioning of the normal gut epithelium.

CJH: Can you perhaps identify one other area outside cancer which is of current molecular genetic interest?

AFM: A major recent advance has been identification of the haemochromatosis gene. This is probably the commonest inherited disease. It is estimated that $10 \%$ of the population carry a haemochromatosis mutation. We don't yet know what impact it may have on other gastrointestinal diseases. For example, my colleagues often tell me that only about $10 \%$ of heavy drinkers seem to develop alcoholic liver disease. It is intriguing to wonder whether heavy drinkers who develop cirrhosis may be predisposed by virtue of carrying a mutant haemochromatosis gene.

CJH: They often have iron loading which is rather casually attributed to iron in the alcohol.

AFM: Absolutely, and it is only when these genes are available for study that people with clinical experience who know about alcoholics and their iron concentrations start to put two and two together. So the discovery of the 
haemochromatosis gene was very important. It wasn't done in the UK but I think distinguished groups in Oxford, Cambridge, Cardiff, and at King's have kept haemochromatosis research in the UK very much at the international forefront for the past decade. I hope they will now take advantage of the cloning of this gene to study its importance further.

CJH: How about looking ahead?

AFM: Molecular understanding of oesophageal cancer will probably increase in the near future. There we have a real problem with Barrett's oesophagus. Many people are running Barrett's screening clinics, but what should be recommended in terms of surgical intervention for Barrett's? We have a great need for increased molecular understanding of carcinoma of the oesophagus because there are shortcomings in our clinical management of that condition at present. I hope to see similar molecular insights into gastric carcinoma emerge. Whether or not $H$ pylori turns out to be an underlying cause for this remains to be seen. I would like to see our understanding of carcinoma of the pancreas increase further. We need some way of identifying patients at risk of this malignancy much earlier. We also need some way of identifying individuals who are at increased relative risk of developing the condition for whatever potential screening processes might be contemplated.

CJH: Perhaps you might now like to predict the major advances which will occur in gastroenterology in the next 10 years?

AFM: Well, I can guarantee to be wrong . . but I think we're going to see a number of the genes cloned that underpin the development of inflammatory bowel disease. I think that's inevitable. I wouldn't be at all surprised if we start to see a few genes emerging that are implicated in irritable bowel syndrome and I think that will cheer up many practising gastroenterologists in terms of having something tangible to offer in that condition. Other interesting things may emerge. Molecular markers may be developed which will enable us to answer questions like: which patients with inflammatory bowel disease are likely to develop carcinoma? What the molecular studies of the future may tell us is that not all of these patients are going to develop cancer, but some of them are at very high risk of doing so. I think that without question gene therapy will be attempted for a number of gastrointestinal malignancies on the grounds that in conditions like pancreatic cancer and advanced colorectal cancer there is absolutely nothing else to offer and so its almost unethical not to be contemplating some of these revolutionary approaches.

Over a slightly longer time frame, I can see much wider use of transplantation in treatment of gastrointestinal disease. I see pancreatic and small bowel transplantation becoming rather more commonplace. I think our molecular insights will enable us to identify more aetiological agents in diet which will have an impact on gastrointestinal health and disease. An example of how molecular insights give us an understanding that works at a clinical level would be the current studies on the use of nonsteroidal anti-inflammatory drugs in a preventative sense in colorectal cancer. A number of people, including John Burn in Newcastle, are looking at aspirin in patients with polyposis to see whether they can postpone the need for colectomy and there are all sorts of exciting new observations concerning prostaglandin synthesis in colonic tumours.

CJH: This field of research is an exciting now and will only become more so. Beyond encouraging people, are there any practical things the BSG should or could do?

AFM: I think there are. A vital part of the health of the discipline is that we do continue to attract bright young clinicians into it and provide them with research training opportunities at the earliest possible stage. The BSG ought to be very strongly encouraged to sponsor training fellowships. I don't believe that such fellowships should be focused entirely on providing laboratory experience. I also think that the BSG does have an important role to play in interacting with and attempting to influence the MRC and the Wellcome Trust to continue to support research in gastroenterology with enthusiasm.

CJH: Thank you very much indeed. 


\section{'And time future contained in time past'}

(TS Eliot)

Sir Francis Avery Jones is interviewed by Professor Michael J G Farthing

First, I would like to thank you for inviting me to come and talk to you. Second, I would like to apologise to you. It was some years ago, I think in 1987, that you gave the BSG Medal Lecture on giardiasis. I was not able to attend so I want to apologise to you

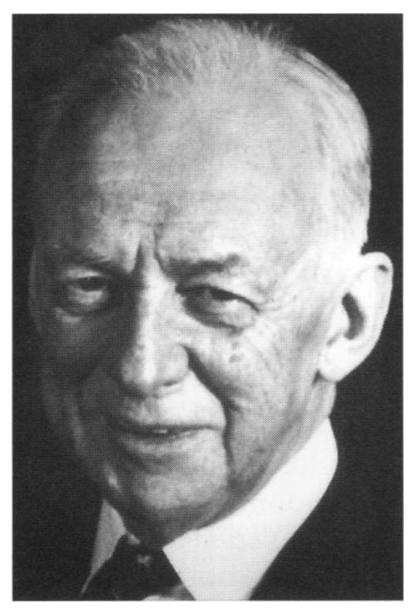
for that.

I would like to tell you briefly about the first time that I saw giardia. I shall go back to about 1934 when I was very fortunate to be house physician to Professor Fraser for two months and then to Professor Witts for a year, and then to Professor Christie. We had a patient on the ward who had intermittent fever, a temperature of up to $105^{\circ} \mathrm{F}$. All the investigations were negative, but then they remembered that we had not performed a duodenal intubation, so I was detailed off to do one. I put some duodenal fluid under the microscope and I was very puzzled. I got hold of Dr Bodley Scott and he looked down the microscope and he said it was just like the Bishop of Birmingham; the Bishop was a very rotund gentleman. There were many pear-shaped objects floating about in the fluid; that was the first occasion that I saw giardia and I was very pleased.

MJGF: What a wonderful story. Did Bodley Scott identify the organism?

Sir Francis: No, he didn't recognise it. He only acknowledged the fact that it looked like the Bishop of Birmingham!

I have spent a lifetime in gastroenterology, but for the past 15 years I have been retired. It took me a little time to get myself fully retired, but when I did, I said to myself that I wanted to leave gastroenterology to my successors. I attend the BSG and the annual Research Medal Lecture, and I continue to read Gut and a number of other gastroenterology journals; having the good fortune of receiving a number of free subscriptions! I decided that there were two sides of the coin. The first side I had been working on for many years and this was concerned with the gut itself. I decided to leave that behind and look at the other side; the food that goes into the gut and the effect that food has on the gut itself. I turned my attention to human nutrition. Every month I read the vari- ous nutritional journals and I have a number of 'moles' overseas, in Scotland, London and elsewhere so that I have had a steady supply of reprints.

MJGF: Why did you decide to make this change? Or perhaps it was not such a great change as your first consultant post at The Central Middlesex was linked with dietetics.

Sir Francis: That's quite true. After the war, in 1950, the BMA organised a working party on food and health; there were about 20 of us, I think, in the working party. Lord Horder was the chairman, and I was the chairman of the Clinical Committee. We produced a report that emphasised the extraordinary good health of the population at home during the war, which at that time was unexpected. The prisoners of war coming back from the Far East or from Germany, were astonished at how well their children had grown up and were 'bright eyed and bushy tailed'.

MJGF: Despite the deprivation of those war years?

Sir Francis: Yes, they were delighted at the health of the people at home. Sir Jack Drummond and Lord Woolton issued a great number of interesting brochures and one of them was on the health and beauty of women at work in the fields and factories!

That is where my interest in human nutrition stemmed from, and I used that as a starting point.

MJGF: What are the areas in nutrition that have interested you the most over the years and what should we be looking at in the future, particularly those interventions that might modify human disease?

Sir Francis: The micronutrients particularly attracted my interest. Frederick Gowland Hopkins, later knighted and a Nobel prize winner, declared in 1906 that there were accessory food factors to explain scurvy and beri beri and one or two other diseases. He set to work with a team in England and around the world to discover the links. He died in 1954. By that time he had discovered nearly half of the vitamins and minerals we know today. That was such a tremendous discovery, and it again attracted my interest very much.

This was not the only aspect of food that appealed to me. I looked at the consistency of food. I realised that some food stimulated the satiety centre more than others. Just recently, in mid-morning in Chichester, nearly all the men in summer wear I saw walking along the street had a 'pot', a big pot belly. Then, I went up to Edinburgh and Inverness and I saw exactly the same thing. I realised that this was a national 
problem; it was what the nutritional task force had been talking about, the increase of obesity. I went to the Chichester Observer and I said to them, 'Is Chichester the pot city of the South?' They regarded this as a good question and the editor sent one of his reporters plus a photographer to interview me. This same, overweight reporter is coming to see us this week and has already managed to lose some weight, and all I told him to do was to have ordinary meals (not quite as much as he was used to perhaps) but just ordinary meals, and in addition to have plenty of 'munchy, crunchy' food. In other words, fruit, vegetables, cereals, and nuts and so on. This he has done, he has been losing weight cheerfully while doing his work as a reporter.

MJGF: Did you ever do any work yourself on the variable effect of foods on satiety or is it something that you have just observed over the years?

Sir Francis: I have not done any work myself, but at the present moment I am collecting material for a letter to Nature on this topic. I shall point out that one does not see, as a rule, animals that are overweight; horses, even retired horses, and certainly ones in training, are not overweight. The reason I suggest they are not overweight is that all mammals have a satiety centre. The munchy, crunchy regime, after a time turns off their satiety centre and so it is a question of the consistency of the food as well as the calories. I would postulate, although I cannot prove it, that the reason for this extraordinary increase in obesity is because so much of modern food has been packaged, processed and re-constituted; sugar and fat have been added which has made it much more interesting in a way, much more easy to swallow, more 'moreish'. I think it is this 'moreish' character of the food that is the central cause of the obesity that we now see. People are not aware that they are taking so many 'hidden calories'

MJGF: During the past few years there has been an increasing use of liquid diets for the treatment of Crohn's disease. Is this something that has caught your attention? Do you think it is an important development or is it a fashion that will come and go?

Sir Francis: I think it is a phase which is passing and passing rapidly. I do not think that there is anything at all specific about liquid diets either for peptic ulcers or for Crohn's disease. The picture for Crohn's disease is becoming very much clearer. I think the recent work on measles affecting the mother during pregnancy is extremely interesting.

MJGF: You find the measles story an attractive hypothesis?

Sir Francis: Undoubtedly. I have looked at the scientific basis and so far it has convinced me.

MJGF: What do you see in the future? Do you think there are any dramatic new treatments for inflammatory bowel disease? To be frank, the treat- ments that we have today are much the same as treatments we had when you left the Health Service.

Sir Francis: I think that it is quite true, that there haven't been big changes in treatment. But, I think that if we know the cause then we are half-way to the solution.

MJGF: May I ask you to turn your thoughts to one of your old loves - peptic ulcer and your seminal work on bleeding ulcers. Did you ever imagine, in the 1950s when you were doing this work, that the cause of an ulcer was going to be an infective agent?

Sir Francis: No, I don't think I did. What I did in 1952 was spend quite a time in Melbourne with Professor Ian Wood who was a great expert on gastritis. I remember looking down a microscope, I can remember this perfectly well to this day, debating with him whether this was due to an organism or whether this was due to an autoimmune disease. I debated with him whether he should have a microbiologist on his team, but at that time an autoimmune explanation really seemed more likely.

In 1960, I had a vacancy, and I discussed with my colleagues at The Central Middlesex whether we should have a microbiologist as a member of our team. Again, we looked down our microscope and decided there was not enough evidence. It was a highly complex field and we felt we were better to wait.

MJGF: Did you ever think about culturing gastric biopsy specimens or was it only microscopic appearances that you were interested in?

Sir Francis: I did not culture, I could have done, but I did not. I myself have had a duodenal ulcer.

MJGF: Did you make the diagnosis of ulcer yourself?

Sir Francis: No, I didn't make the diagnosis myself.

Lady Avery Jones: No. He had a barium meal and when the films came back and were put up he jokingly said 'now I know I have been infected by my patients. I've got a DU.'

MJGF: You had a barium meal and not an endoscopy?

Sir Francis: No, I had an endoscopy as well and I had very fierce oesophagitis and a duodenal ulcer.

MJGF: How did you treat your ulcer in 1970?

Lady Avery Jones: Treated it roughly I would have said!

Sir Francis: Yes, very true.

MJGF: Did it ever recur?

Sir Francis: Yes, I had to be very careful for a number of years. But then I got myself, as soon as it appeared, on to ranitidine. That was excellent-one dose every night at bedtime. I have had no trouble since.

MJGF: How do you see the future of peptic ulcer disease now that we have found Helicobacter 
pylori? Do you think that ulcers will just disappear?

Sir Francis: I do not think that ulcers will disappear. I think for a very, very long time we shall have our quota and I think one of the reasons is the enormous use of non-steroidal antiinflammatory drugs. There are still cases of sudden perforation. I keep on telling people that they haven't paid sufficient attention to mucus. In my opinion the central trouble is mucus. The quality of the mucus being formed is impaired which makes the stomach more susceptible to an ulcer.

MJGF: What do you think are going to be the major clinical challenges for young gastroenterologists over the next 10-15 years? What do you see as the areas that are going to be important clinically and important for us to direct our research energies towards?

Sir Francis: I think the whole spectrum of gastroenterology, with modifications here and there, will remain very much as now. And so I think the younger gastroenterologists should say to themselves if they want to continue in this specialty, that it is a specialty that is based on general medicine, that you and I and everyone else always had a general medical job to start with before they can become a gastroenterologist.

I would encourage someone to take up gastroenterology; I would also encourage them to look at the wider issues of food, including food in the hospitals. I was talking yesterday to the nutritionist at Ipswich; she has a nutrition team (a manager, pharmacist, physician, etc.) who look at the problem of nutrition as a whole. They track down the patients with malnutrition, sort them out and treat them. I think they are getting to the bottom of the problem of bad nutrition in hospitals.

MJGF: Why do you think the profession is so slow to recognise the importance of malnutrition in our patients?

Sir Francis: Our training is very much to blame. People are excited by techniques-the excitement with endoscopy is what appeals to young doctors.

MJGF: Do you think too much looking has inhibited thinking?

Sir Francis: I think the influence of endoscopy has been an enormous. I was partly responsible for it. However, what you say is partly true. But people are changing. I think they are beginning to see that there is another side to the coin. They are thinking about the food that goes into the gut, as well as the gut itself.

MJGF: How do you think we can change the situation, and make our trainees and colleagues within the profession more aware of the importance of nutrition?

Sir Francis: I think that in every hospital there should be a nutrition committee and a food committee; I think the young students should attend. They should see what is going on-they should see the importance of weight.
The simple anthropometric measurements should be part of their training.

MJGF: One of the difficulties, as you rightly say, is that people are interested in techniques and technologies, and nutrition doesn't always seem to be very exciting. I wonder how we could give it a bit of glitz?

Sir Francis: Yes, I know. This was the trouble with gastroenterology at the time of Arthur Hurst. The general physicians were not interested in gastroenterology and the medical students at Bart's, where I was teaching, were not interested either.

MJGF: What were they interested in?

Sir Francis: They were interested in hearts-in murmurs, systolic murmurs and things like that. And that was dull! It was a long time before I realised that a medical ward anywhere, was dull! My answer to that problem was to keep my surgical patients-if a patient needed a gastrectomy, they would stay in my ward and I would look after them postoperatively.

MJGF: I know at 'The Central'you had a combined medical-surgical ward and you took part in the postoperative care of the patient. How revolutionary was it at that time?

Sir Francis: Completely-I was the only person in the country to do this and I also had a diet kitchen on the ward. I think I was the only person to do this-the surgeons liked it because it gave them extra beds.

MJGF: Yes, I bet-they could be off operating rather than burdened with postop care! Finally, Sir Francis, I would like to ask you about the beginnings of the BSG; how did it all start?

Sir Francis: Sir Arthur Hurst conceived the idea of a Gastroenterological Club in 1936, and the first meeting took place in London in 1937. I was taken by Professor Leslie Witts who was my chief at Bart's at the time.

MJGF: How many people were present at this first meeting?

Sir Francis: Sir Arthur Hurst had invited 40 physicians from all over the country to the inaugural meeting. Having decided to have a British Society of Gastroenterologists, their first move was to appoint a surgeon and a radiologist, Sir John McNee and Dr S W Patterson, as members of the Society.

MJGF: What were the main topics for discussion?

Sir Francis: Alkalosis and gastroscopy. Alkalosis because of the excessive use of soluble antacids in peptic ulcer disease, and gastroscopy because of the use of the semi-flexible gastroscope developed by Rudolf Schindler and Wolfe, an optician.

MJGF: Did you meet Sir Arthur Hurst? What sort of man was he?

Sir Francis: Yes, a number of times. He was an inspired leader, a great man and a remarkable physician. I wrote about him in a history of gastroenterology in the Companion of Oxford Medicine in 1986. 
'He was born in Bradford, the family name being Hertz and of German origin; the great physicist, Heinrich Rudolf Hertz, was his father's cousin. Hurst went to Oxford University and then to Guy's Hospital. He was awarded the Radcliffe Travelling Fellowship and spent some time in Munich, Strasbourg, and Boston where he came into contact with $\mathrm{W}$ B Cannon's pioneer X-ray studies on cats. On his return to England he began observations in man and in 1908 published a very detailed account of movement in the stomach, intestine, and colon. These observations were essential to the understanding of diseases and disorders of the digestive system. His early studies in man were followed by detailed pioneer clinical observations particularly in relation to gastric ulcer, duodenal ulcer, achalasia of the cardia, and constipation. He published his first book Constipation and Allied Disorders in 1909. He was appointed to the staff of Guy's Hospital at the age of 27 , as physician to the electrical department. He served in the Royal Army Medical Corps during the First World War and his studies, thanks to his powerful personality, led to his remarkable success in the treatment of war neurosis. In the post-war years he built up a great international reputation because of the originality of his approach to common clinical problems, at the same time maintaining close links with physiology. He was, indeed, a clinical physiologist but practising as a general physician with a wide interest in cardiology, neurology, allergy, and psychoneurosis; all of these formed a background to his life's work in gastroenterology. His weekly open staff round at Guy's Hospital brought visitors from all around the world and his work inspired a number of the rising generation of physicians to develop a special interest in gastroenterology.'

(Extract from The Oxford Companion to Medicine. Walton JN, Beeson PB, eds. 1986. By permission of Oxford University Press.)

MJGF: Thank you, Sir Francis, for giving us your time. Perhaps I could also thank you personally on behalf of the BSG for the enormous contribution that you have made to the development of gastroenterology in the UK. 